Article

\title{
Nanoscience Supporting the Research on the Negative Electrodes of Li-Ion Batteries
}

\author{
Alain Mauger ${ }^{1}$ and Christian M. Julien ${ }^{2, *}$ \\ 1 Sorbonne Universités, UPMC Université Paris6, Institut de Minéralogie et Physique de la Matière \\ Condensée (IMPMC), 4 place Jussieu, Paris 75005, France; \\ E-Mail: alain.mauger@impmc.jussieu.fr \\ 2 Sorbonne Universités, UPMC Université Paris6, Physicochimie des Electrolytes et Nanosystèmes \\ Interfaciaux (PHENIX), UMR 8234, 4 place Jussieu, Paris 75005, France \\ * Author to whom correspondence should be addressed; E-Mail: christian.julien@upmc.fr; \\ Tel.: +33-144-273-534 Fax: +33-144-278-250.
}

Academic Editors: Andy (Xueliang) Sun and Xifei Li

Received: 28 October 2015 / Accepted: 2 December 2015 / Published: 16 December 2015

\begin{abstract}
Many efforts are currently made to increase the limited capacity of Li-ion batteries using carbonaceous anodes. The way to reach this goal is to move to nano-structured material because the larger surface to volume ratio of particles and the reduction of the electron and Li path length implies a larger specific capacity. Additionally, nano-particles can accommodate such a dilatation/contraction during cycling, resulting in a calendar life compatible with a commercial use. In this review attention is focused on carbon, silicon, and $\mathrm{Li}_{4} \mathrm{Ti}_{5} \mathrm{O}_{12}$ materials, because they are the most promising for applications.
\end{abstract}

Keywords: nano-materials; negative electrodes; Li-ion batteries

\section{Introduction}

Since they became commercialized, all the lithium-ion batteries are equipped with graphitic carbon anodes. The graphite can reversibly absorb lithium up to the concentration $\mathrm{LiC}_{6}$. One advantage of using carbon is its very good electrical conductivity, and good ionic conductivity. It must be protected against side reactions with the electrolyte, but chemists have found solvents such as ethylene carbonate that allow the formation of a stable solid-electrolyte interface (SEI). However, the theoretical capacity associated to the cycles between $\mathrm{C}_{\text {and }} \mathrm{LiC}_{6}$ is $372 \mathrm{mAh} \cdot \mathrm{g}^{-1}$. Therefore, many efforts in research are 
currently made to increase this limited capacity. The way to reach this goal is to move to nano-structured anodes for three reasons: (a) when the size of the active particles is decreased to the nano range, the larger surface to volume ratio implies a larger specific capacity, and a larger contact area with the electrolyte leading to high lithium ion flux across the electrode/electrolyte interface; (b) the reduction of the size of the particles implies a reduction of the length of the electron and Li path inside the particles. This migration distance inside the particle is the limiting factor for conductivity, because after the electron has reached the surface of a particle it is driven to the current collector in a conductive medium, while the $\mathrm{Li}^{+}$ion is driven to the counter-electrode through an electrolyte which has a much larger ionic conductivity than Si. Therefore, the overall lithium diffusion and electrical conductivity of the assembly of Si particles are improved by the reduction of the size of Si particles to the nano-range, leading to batteries with enhanced power capability; and (c) the intercalation of lithium is accompanied with a dilatation of the particles, which may result in the formation of cracks, or even pulverization when the particle size is in the micron range. Furthermore, nano-particles can accommodate such a dilatation/contraction during cycling, resulting in a calendar life compatible with a commercial use. The first idea is to keep carbon under nano-size in form, such as nanotubes, or graphene, but attempts are also currently made to replace carbon by other materials with higher theoretical capacity. Among them, silicon is considered as most promising, because it has a very large theoretical capacity, and because we can benefit from the silicon technology in electronics to synthesize nano-structured particles of different shapes. On the other hand, even with the size of Si particles is reduced to the nano-range, the lithiation/delithiation must be a slow process to limit the mechanical stress, meaning that the power available with batteries equipped with a Si-based anode is small. Therefore, other efforts have been made to obtain Li-ion batteries that have much higher power, even if their energy density is much smaller. $\mathrm{Li}_{4} \mathrm{Ti}_{5} \mathrm{O}_{12}$ is considered as the most promising anode with this respect. We do not intend to review here all the works devoted to anode materials. We only report recent results and progress that illustrate the outstanding improvements in the electrochemical performance of Li-ion batteries, resulting from the reduction of the size of the active particles to the nano-scale. More exhaustive reviews devoted to anodes can be found in review papers and books [1,2]. Additionally, attention is focused here on the carbon, silicon, and $\mathrm{Li}_{4} \mathrm{Ti}_{5} \mathrm{O}_{12}$ materials, because they are the most promising for applications. Many other oxides are currently under investigation in laboratories, and we only guide the reader to the recent book [2] that reviews the state of the art on them.

\section{Nano-Structured Carbon}

The quantum confinement modifies the electronic and structural properties, which is beneficial to the storage capacity by removing the limitation of the capacity to $372 \mathrm{mAh} \cdot \mathrm{g}^{-1}$ [3-8]. The increase of the number of storage sites available for the lithium ions in small closed spaces in nano-structured carbon is another reason invoked to explain the large capacities that have been observed [9-11]. Carbon nano-rings with $20 \mathrm{~nm}$ outer diameters and 3.5-nm wall thickness deliver a capacity $1200 \mathrm{mAh} \cdot \mathrm{g}^{-1}$ over hundreds of cycles at the current density of $0.4 \mathrm{~A} \cdot \mathrm{g}^{-1}$. At the higher current rates of $45 \mathrm{~A} \cdot \mathrm{g}^{-1}$, the capacity is still $500 \mathrm{mAh} \cdot \mathrm{g}^{-1}[12]$.

Carbon nanotubes, especially single wall carbon nanotubes (SWCNTs) are promising, as their reversible capacity is estimated to be $1116 \mathrm{mAh} \cdot \mathrm{g}^{-1}$ in stoichiometric $\mathrm{LiC}_{2}$ owing to the intercalation of 
lithium into stable sites located on the surface of pseudo-graphitic layers and inside the central tube, as well [13-16]. Indeed, a purified single-wall carbon nanotube (SWCNT) obtained by laser vaporization delivered a capacity larger than $1050 \mathrm{mAh} \cdot \mathrm{g}^{-1}$ [17]. The best result with multi-wall carbon nanotubes (MWCNT) has been obtained through directly applying a $10 \mathrm{~nm}$ thick layer of $\mathrm{Al}_{2} \mathrm{O}_{3}$ by atomic layer deposition (ALD) on the pre-fabricated electrodes made from bare powders. The resultant MWCNT anode demonstrated a stable capacity of $1100 \mathrm{mAh} \cdot \mathrm{g}^{-1}$ in 50 charge-discharge cycles at the current rate of $372 \mathrm{~mA} \cdot \mathrm{g}^{-1}$ [18]. The $\mathrm{Al}_{2} \mathrm{O}_{3}$ coating effectively blocks electron tunneling to the adsorbed EC molecules of the electrolyte and, thus, decreases the decomposition of the electrolyte [19]. Note that bad results are obtained when coating bare electrode materials via ALD and then fabricating the coated materials into electrodes, because $\mathrm{Al}_{2} \mathrm{O}_{3}$ is insulating and inhibits the electron conduction path between the anode and the current collector [20]. Note, however, that these results are obtained at the laboratory scale and are far from the results obtained with commercial products. Commercial MWCNTs have a typical capacity close to $250 \mathrm{mAh} \cdot \mathrm{g}^{-1}$. After purification, the capacity raises to a $400 \mathrm{mAh} \cdot \mathrm{g}^{-1}$. Moreover, the MWCNTs show a tendency to suffer from Li-induced embrittlement [21], because their close structure does not allow expansion of graphene sheets in the c-axis or radial direction, as in graphite, when Li is inserted, thus inducing large stresses during cycling. Despite the promising results we have reported, the carbon nanotubes have not found a place in the industry of the lithium-ion batteries, essentially because of their cost and the difficulty to prepare them free of any large structural defects and high voltage hysteresis.

Graphene looks more attractive, because of its very good conductivity and mechanical strength [22-26]. The theoretical capacity is much larger than that of graphite, namely $780 \mathrm{mAh} \cdot \mathrm{g}^{-1}$ if $\mathrm{Li}$ ions can be absorbed on both sites up to the stoichiometric $\mathrm{Li}_{2} \mathrm{C}_{6}$, and $1116 \mathrm{mAh} \cdot \mathrm{g}^{-1}$ if the $\mathrm{Li}$ ions can be trapped at the benzene rings in a covalent bonding up to $\mathrm{LiC}_{2}$ stoichiometry $[23,27,28]$. The main difficulty with graphene is its tendency to agglomerate, which is a major cause of the aging upon cycling. To avoid this re-stacking of the graphene sheets, the graphene can be doped. Nitrogen, which has five valence electrons and has a comparable atomic size with $\mathrm{C}$, is the most popular dopant, forming a strong covalent $\mathrm{C}-\mathrm{N}$ bond breaking the charge neutrality on $\mathrm{C}$. This doping generates a disorder in the honeycomb lattice of pristine graphene, which may help in the prevention against re-stacking of the graphene sheets, and it donates more electrons to the carbon network, thus increasing the electrical conductivity [29]. An outstanding result has been obtained with a doped hierarchically-porous graphene (DHPG) electrode using graphene oxide, sulfonated polystyrene spheres (S-PS), and poly(vinyl pyrrolidone) (PVP) as precursors through in situ preparation in nickel foam oxide [30]. Electrochemical performance of the doped hierarchically-porous graphene electrodes is shown in Figure 1. During the pyrolysis of the precursor, the graphene was doped in situ by nitrogen atoms from PVP and sulfur atoms from S-PS. This electrode delivered a high-power density of $116 \mathrm{~kW} \mathrm{~kg}^{-1}$, whereas the energy density is left as high as $322 \mathrm{Wh} \cdot \mathrm{kg}^{-1}$ at $80 \mathrm{~A} \cdot \mathrm{g}^{-1}$ (about $10 \mathrm{~s}$ to full charge) with a good capacity retention for 3000 cycles with high capacities in the temperature range $20-55^{\circ} \mathrm{C}$. This last result shows that doping is beneficial to the performance of graphene as an anode. In a different approach, composites of graphene with nanoparticles of another electroactive anode material have been investigated, since the grafting of the nanoparticles on the graphene sheets prevents the re-stacking. In addition, the elastically strong, flexible, and conductive graphene can accommodate the volume changes suffered by the particles upon cycling, thus benefiting the structural stabilization of the nanoparticles and the cycling life. Actually, doped graphene 
can be used, thus combining the two effects of doping and grafting. For instance, $\mathrm{Co}_{3} \mathrm{Sn}_{2} / \mathrm{Co}$ nanoparticles grafted on $\mathrm{N}$-doped graphene tested as an anode delivered capacities of $1600 \mathrm{mAh} \cdot \mathrm{g}^{-1}$ and $800 \mathrm{mAh} \cdot \mathrm{g}^{-1}$ almost constant between the second and the 100th cycle in the voltage range $0.005-3 \mathrm{~V}$, at current densities 250 and $2500 \mathrm{~mA} \cdot \mathrm{g}^{-1}$, respectively [31].
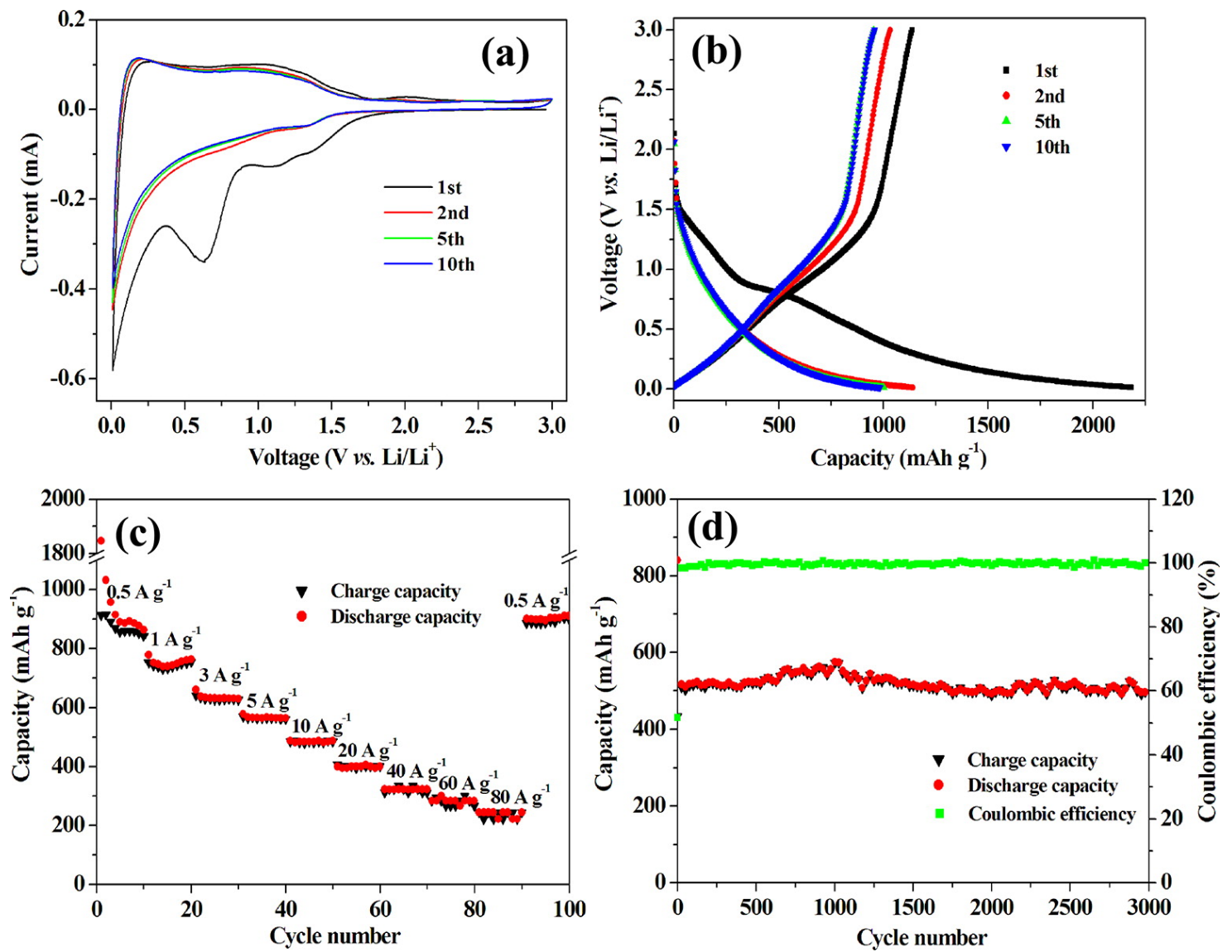

Figure 1. Electrochemical performance of the doped hierarchically porous graphene electrodes. Reproduced with permission from [30]. Copyright The American Chemical Society, 2013. (a) Cyclic voltammograms at a scan rate of $0.1 \mathrm{mV} \cdot \mathrm{s}^{-1}$; (b) charge-discharge curves at $0.1 \mathrm{~A} \cdot \mathrm{g}^{-1}$; (c) capacity over cycling at different current densities; and (d) cycling and Coulombic efficiency at current density of $5 \mathrm{~A} \cdot \mathrm{g}^{-1}$.

\section{Silicon Anodes}

Silicon is cheap. Its capacity is very large: $4200 \mathrm{mAh} \cdot \mathrm{g}^{-1}$ when lithiated to $\mathrm{Li} 4.4 \mathrm{Si}$ [32]. The onset voltage potential is $0.3-0.4 \mathrm{~V}$ above the $\mathrm{Li}^{0} / \mathrm{Li}^{+}$redox potential, which averts the safety concern of lithium deposition encountered with the graphite anode. That is why a tremendous amount of work has been done on Si-based anodes. The difficulty with Si, which has postponed its commercial use in the battery industry is the large variations of the volume during the charging/discharging process [33-39]: from $\mathrm{Si}$ to $\mathrm{Li} 4.4 \mathrm{Si}$, the volume expansion is $420 \%$ [40-44]. This large volume change upon cycling results in the cracking and pulverization of the Si particles and disconnection of some of the particles from the conductive carbon and from the current collector [45-47]. Therefore, the decrease of the size to the nano-range is mandatory to relieve the stress [48]. Only nanostructured electrodes can absorb the strains 
associated to the change of volume, and avoid cracking $[38,49]$. In addition, the decrease of the diameter of the particles upon delithiation decreases with the size of the particles, so that smaller particles can keep contact with the matrix, allowing for full extraction of the lithium. When the potential of the anode is lower than $1 \mathrm{~V}$ with respect to $\mathrm{Li}^{0} / \mathrm{Li}^{+}$, the decomposition of the organic electrolyte at the surface of the particles forms the solid-electrolyte interface (SEI). The SEI must be dense and stable to prevent further side reactions to occur. However, the large volume change makes it challenging to form a stable SEI, as it can result in a breaking of the SEI. Then, a new particle of Si can be exposed to the electrolyte, resulting in the formation of another SEI that becomes thicker and thicker upon cycling [50]. This is why the efforts on silicon anodes have been focused on the synthesis of nano-particles of different geometries, and also on the protection of the Si particles against side reactions with the electrolyte.

\subsection{Thin Films}

To obtain good results with thin films, the silicon must be amorphous, since crystalline Si expands anisotropically upon lithiation, primarily in the $<110>$ direction [51-53]. This anisotropy contributes to increasing the stress and strains in the material. In addition, it should be doped to improve the electrical conductivity. For example, a $50 \mathrm{~nm}$-thick Si film n-doped with phosphor delivered a capacity $3000 \mathrm{mAh} \cdot \mathrm{g}^{-1}$ for the case of $12 C$ test, which could be kept during 1000 cycles (Figure 2).
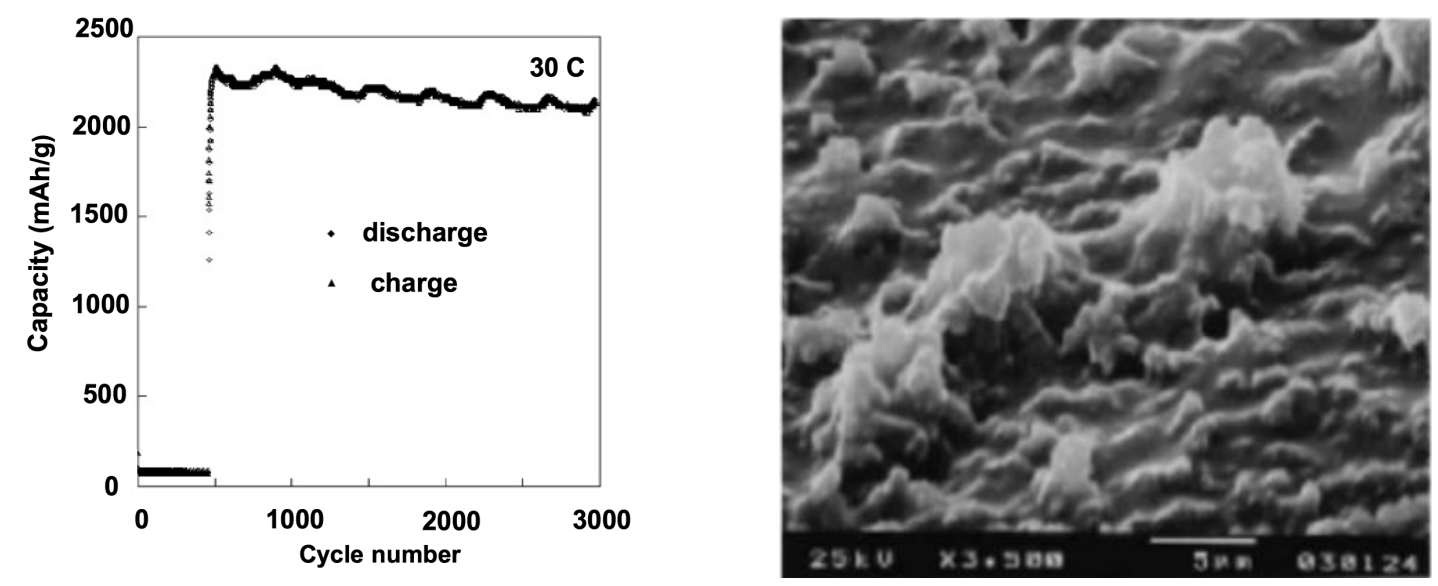

Figure 2. Capacity retention of $500 \AA \AA$ thick n-Si film during charge/discharge cycling with $30 C$ rate charge/discharge in propylene carbonate containing $1 \mathrm{~mol} \cdot \mathrm{L}^{-1} \mathrm{LiClO}_{4}$. The scanning electron microscopy (SEM) image of the Si film is shown after 1000 cycles. Reproduced with permission from [54]. Copyright Elsevier, 2004.

Additionally, in the case of the heavy load of the $30 C$ rate, the charge/discharge capacity was still over $2000 \mathrm{mAh} \cdot \mathrm{g}^{-1}$ even after 3000 cycles [54]. This result illustrates that long cycle life up to 3000 cycles can be obtained with Si films prepared either by physical vapor deposition [54,55], or magnetron sputtering [56]. In the latter case, the thickness of the $\mathrm{Si}$ film deposited on $\mathrm{Cu}$ foil was $275 \mathrm{~nm}$. On the other hand, $1 \mu \mathrm{m}$-thick amorphous Si film deposited on $\mathrm{Cu}$ foil delaminates (i.e., peel off the underlying electrode) after few cycles, resulting in loss of electrical contact [57]. The thickness of the Si-film deposited on Ni foil in [54] was $500 \mathrm{~nm}$. Ni develops a passivating layer that acts as a good binding agent between the substrate and the Si film due to the strong affinity of Si to oxygen. 
Nevertheless, even in this case, thicker films gave poorer results [54]. From these experiences, we can infer that the optimum thickness of a Si film is the order of $300 \mathrm{~nm}$ to avoid cracking of the film.

A new strategy of stress relaxation for Si films uses an elastomeric substrate that establishes an alternative route for new electrode design [58]. In that case, the mechanism for stress relaxation is due to the strain induced by charge/discharge cycling. The volumetric strain in Si can buckle the flat Si thin films deposited on soft substrates; such an effect releases the stress in the Si films by equilibrating the electrochemically-induced axial component and buckling induced bending component of the stress.

Poly(dimethylsiloxane) (PDMS) was used as the soft substrate. The fabrication consisted in patterning the top Si (100-400 nm) of silicon-on-insulator (SOI) wafers into ribbons followed by the removal of the buried $\mathrm{SiO}_{2}$ layer $(400 \mathrm{~nm})$. Thin layers of chromium $(5 \mathrm{~nm})$, gold $(100 \mathrm{~nm})$, and chromium $(5 \mathrm{~nm})$ were then deposited in sequence on top of the Si ribbons, followed by oxidization of the top Cr layer. A flat PDMS substrate (300-500 $\mu \mathrm{m}$ thick) was brought into contact with the multilayer structure $\left(\mathrm{Cr}_{2} \mathrm{O}_{3} / \mathrm{Au} / \mathrm{Cr} / \mathrm{Si}\right)$. The microfabrication is shown in Figure 3.

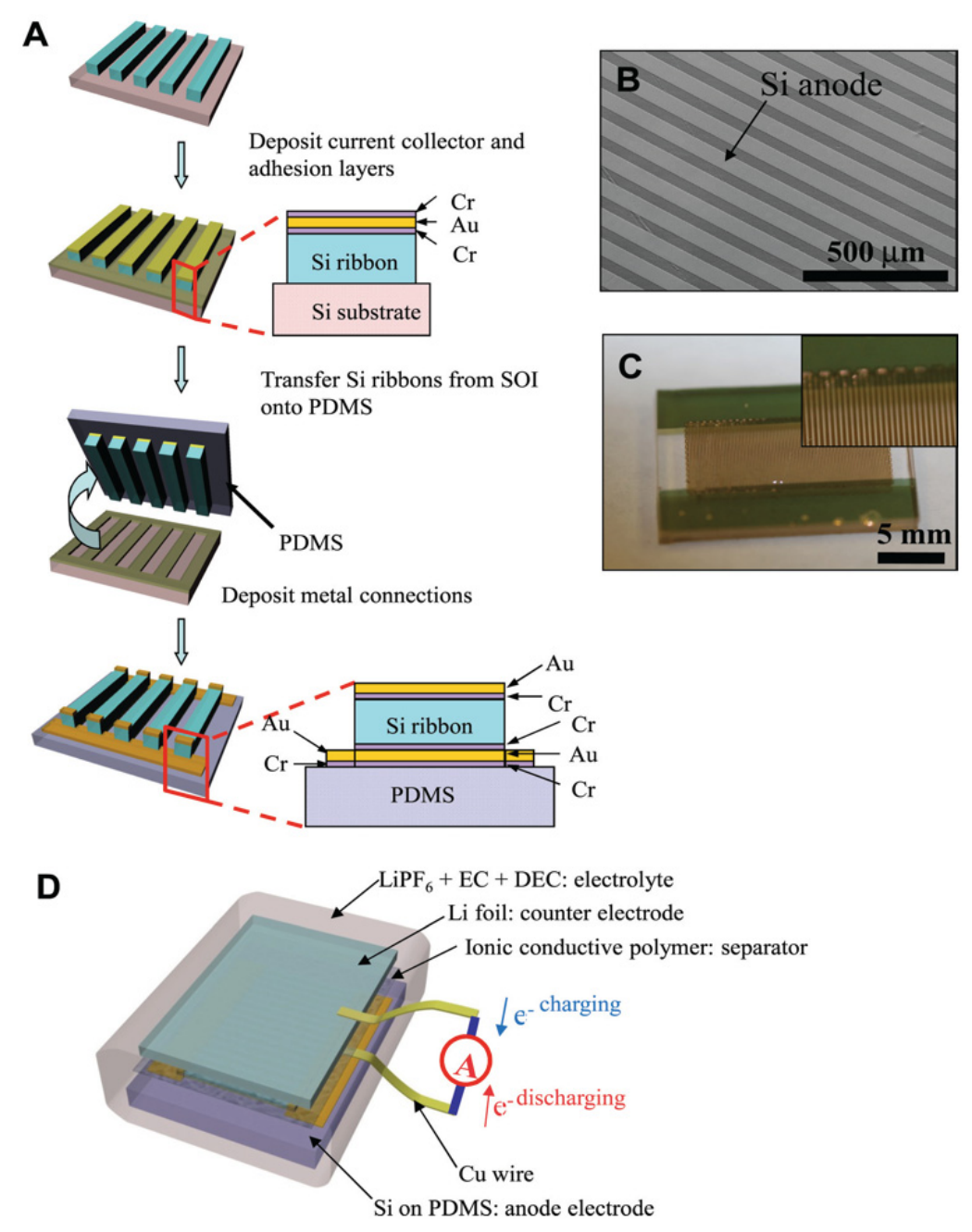

Figure 3. Half-cell lithium ion battery based on Si anodes, produced by microfabrication. Reproduced with permission from [58]. Copyright Wiley, 2012. (A) Schematic steps to fabricate the Si anodes on Poly(dimethylsiloxane) (PDMS) substrates; (B) A SEM image of Si anode on PDMS; (C) Optical images of fabricated anode before assembling; and (D) an illustration of the battery cell assembly. 
The cell was galvanostatically charged and discharged within a voltage window of $0.005-3.000 \mathrm{~V}$ ( vs. $\mathrm{Li}^{0} / \mathrm{Li}^{+}$) at $C / 4$ rate, i.e., this charge/discharge rate is calculated from the theoretical specific capacity of $4200 \mathrm{mAh} \cdot \mathrm{g}^{-1}$ for $\mathrm{Si}(C / 4$ rate is to a current density that allows a full discharge in $4 \mathrm{~h})$. Under such conditions, the cell delivered up to $4137 \mathrm{mAh} \cdot \mathrm{g}^{-1}$ at the first cycle and at $3498 \mathrm{mAh} \cdot \mathrm{g}^{-1}$ at the $500 \mathrm{th}$ cycle. Indeed, the SEM images of the buckled structures (Figure 3B), which are similar to springs, adjust the accumulated stress to avoid cracking and crumbling of the Si electrode, thus keeping the structural integrity and, thus, contributes to better cycling performance. These results show that the recent progress on thin Si films make them competitive with respect to other forms of nano-Si, such as nanowires and nanotubes, with the advantage that the synthesis process for thin films is more scalable.

\subsection{Nanowires and Nanotubes}

The silicon nanowire ( $\mathrm{Si} \mathrm{Nw}$ ) array provides sufficient empty space between the nanowires to accommodate the change in the volume associated to the lithiation/delithiation of lithium. As an example, Figure 3 shows the electrochemical behavior of a battery using porous Si nanowires as the anode and Li metal as the current collector. Growth methods have been reviewed in [59]. The best results are obtained with wires composed of an amorphous shell deposited by chemical vapor deposition (CVD) over an as-grown crystalline core $[38,60]$. The main concern with the CVD method to grow $\mathrm{Si}$ nanostructures is the low yield. For nanowires, it is only $200-250 \mu \mathrm{g} \cdot \mathrm{cm}^{-2}$ or $0.75 \mathrm{mg} \cdot \mathrm{h}^{-1}$ [61], which greatly limits the use of this method for mass production. Nevertheless, the synthesis at the laboratory scale shows that the amorphous shell is able to prevent the initial cracking that takes place in the surface layer upon delithiation and like in the case of the thin films, n-doping with phosphor improves the electrical conductivity and, thus, the performance at high $C$-rates. Such wires delivered $3100 \mathrm{mAh} \cdot \mathrm{g}^{-1}$ after 40 cycles at $C / 2$ rate, without charging voltage limitation. The capacity retention at the $8 C$ rate was still circa $500 \mathrm{mAh} \cdot \mathrm{g}^{-1}$ [62]. In this example, the nanowires were synthesized after Au-catalyzed vapor-solid-liquid (VLS) growth in a hot plate (cold wall) reactor. The temperature in the gas phase above the furnace decreases rapidly, so that after a short period of vertical growth in the stagnant layer, the wires tend to kink and curve their growth direction towards the substrate. Due to this change in growth direction, the Nws became highly entangled. The entanglement has two advantages. Firstly, the interconnection between the Nws prevents them from detaching from the substrate; and secondly, the quantity of $\mathrm{Si}$ is increased. In [62], it was the order of $1.2 \mathrm{mg}$ per squared $\mathrm{cm}$ of current collector electrode, thus overcoming one of the drawbacks of using nano-materials in battery electrodes, namely the low volumetric energy density [63].

Best results are obtained when the silicon is porous, because the electrolyte can penetrate into the pores, thus increasing the effective area between Si and the electrolyte and, in addition, the pores act as buffers for the reduction of stresses during cycling. Nanoporous silicon nanowires of 5-8 $\mu \mathrm{m}$ length and with a pore size of $10 \mathrm{~nm}$ obtained by etching according to a process that is suitable to mass production delivered a capacity of $2400 \mathrm{mAh} \cdot \mathrm{g}^{-1}$ with an initial coulombic efficiency of $91 \%$ and stable cycle performance [64].

Not surprising, the best result have been obtained with porous doped silicon nanowires which delivered 2000, 1600, and $1100 \mathrm{mAh} \cdot \mathrm{g}^{-1}$ at rates $0.5 C, 1 C, 4.5 C$, respectively, and recorded 2000 cycles with a capacity remaining above $1000 \mathrm{mAh} \cdot \mathrm{g}^{-1}$, even achieved at $4.5 C$ [32]. Both the pore 
diameter and the wall thickness were about $8 \mathrm{~nm}$. It should be noted that this high rate capability has been obtained at a low mass loading of $0.3 \mathrm{mg} \cdot \mathrm{cm}^{-2}$, a recurrent problem when the nanowires are not entangled like in [63]. That is one of the reasons why the Si Nws anodes are still difficult to compete with graphite anodes. Typical commercialized graphite-based anodes can store a charge of $4 \mathrm{mAh} \cdot \mathrm{cm}^{-2}$, because they use $50 \mu \mathrm{m}$ thick films on the current collector. So, assuming a Si capacity of $3800 \mathrm{mAh} \cdot \mathrm{g}^{-1}$, to obtain the same mass density Nws with their diameter in the $300 \mathrm{~nm}$ range have to be grown, which will limit the rate to around $3 C$ [65]. In another synthesis process, the void space of a template could be filled with the gel-like silicon precursor [66]. Mesoporous Si-carbon core-shell nanowires with a diameter of $6.5 \mathrm{~nm}$ prepared by this process demonstrated a first charge capacity of $3163 \mathrm{mAh} \cdot \mathrm{g}^{-1}$ and retained a capacity at $2738 \mathrm{mAh} \cdot \mathrm{g}^{-1}$ after 80 cycles [67].

Overall, considering the slow growth of nanowires and the low mass loading the thin Si films mentioned in the previous section, which are able to deliver stable capacity of about $1.8 \mathrm{mAh} \cdot \mathrm{cm}^{-2}$ for 200 cycles, look more competitive. Their aging at the scale of 2000-3000 cycles, however, remains to be tested. Another problem comes from the slow growth of nanowires so that the mass production at the industrial scale is not possible yet.

Nanotubes have the same advantages and drawback as nanowires. In particular, their performance is good, as it is easy to connect them electrically to the current collector [32,68-70] (see Figures 4 and 5). Another advantage with respect to the nanowires is the very large surface area accessible to the electrolyte since lithium ions can intercalate from both the interior and the exterior of the nanotubes. As a result, the capacity $3200 \mathrm{mAh} \cdot \mathrm{g}^{-1}$ has been reached, with capacity retention of $89 \%$ after 200 cycles at $1 C$ rate [70].
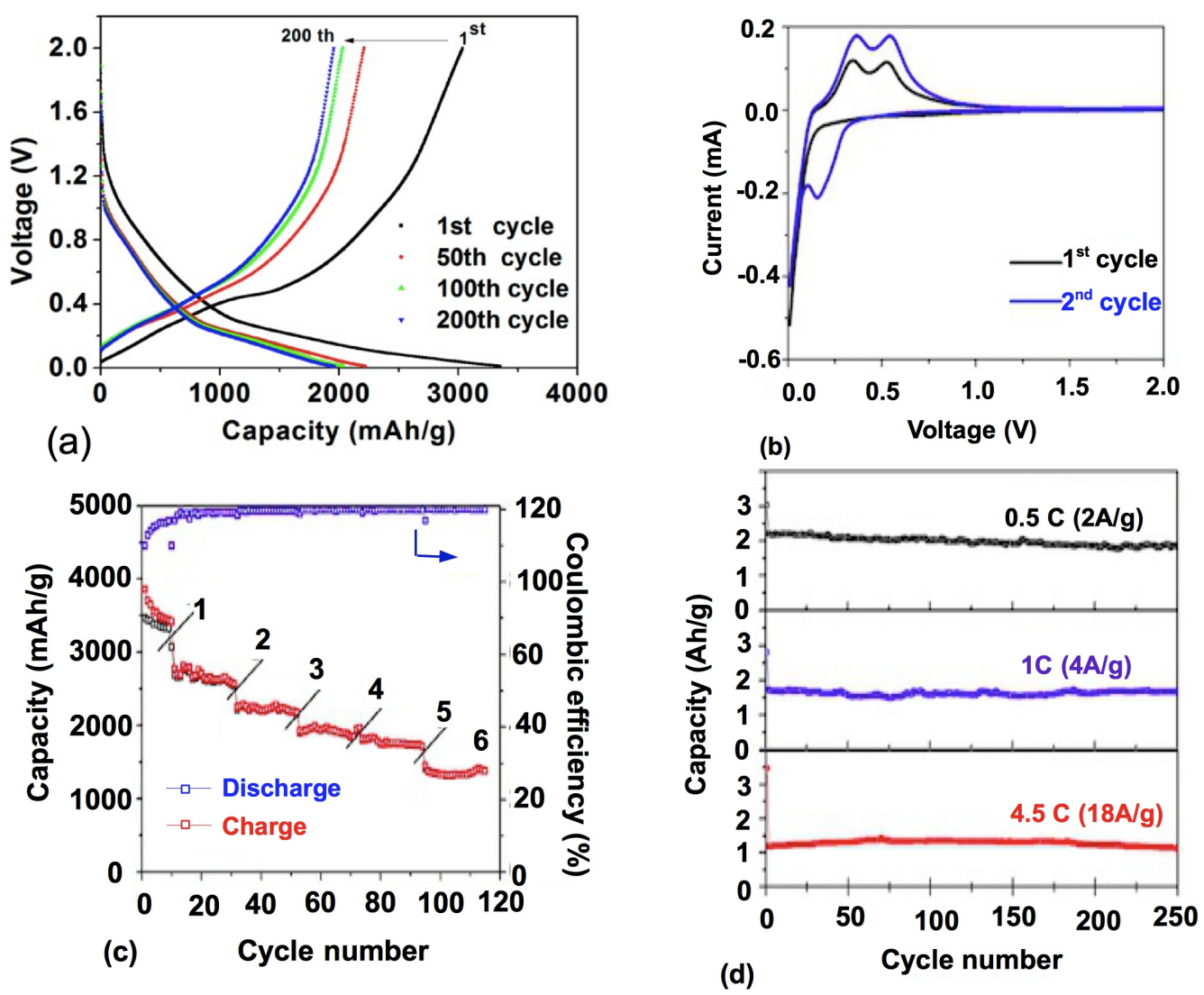

Figure 4. Cont. 


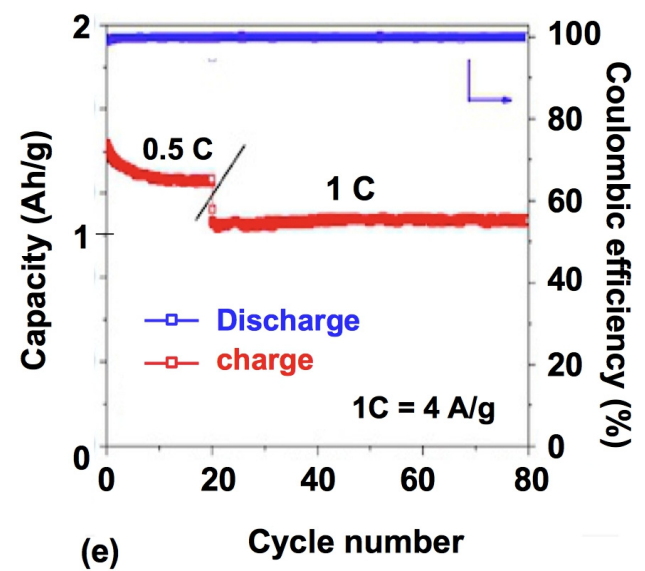

Figure 4. Electrochemical performance of a battery using porous silicon nanowires as the anode and lithium metal as the current collector (SEM and transmission electron microscopy (TEM) images of the nanowires are shown in Figure 5). Reproduced with permission from [32]. Copyright Wiley, 2012. Si mass loading was around $0.3 \mathrm{mg} \cdot \mathrm{cm}^{-2}$. (a) Charge/discharge profile within a voltage window of $0.01-2 \mathrm{~V} v s . \mathrm{Li}^{0} / \mathrm{Li}^{+}$for the first cycle at a current rate of $0.4 \mathrm{~A} \cdot \mathrm{g}^{-1}$ and the 50th, 100th, and 200th cycles at $2 \mathrm{~A} \cdot \mathrm{g}^{-1} ;$ (b) cyclic voltammetry curves of porous silicon nanowire electrode for the first and second cycles using a voltage window $0.01-2 \mathrm{~V}$ at rate of $0.1 \mathrm{mV} \cdot \mathrm{s}^{-1}$; (c) charge/discharge capacity and coulombic efficiency of porous silicon nanowire electrode at current rates of $0.6,1.2,2.4$, $3.6,4.8$, and $9.6 \mathrm{~A} \cdot \mathrm{g}^{-1}$; (d) charge/discharge capacity of a porous silicon nanowire electrode at current rates of 2,4 , and $18 \mathrm{~A} \cdot \mathrm{g}^{-1}$ for 250 cycles; and (e) charge/discharge capacity of a porous silicon nanowire electrode at current rates of $2 \mathrm{~A} \cdot \mathrm{g}^{-1}(0.5 C)$ and $4 \mathrm{~A} \cdot \mathrm{g}^{-1}(1 C)$ with an additional 2000 cycles.
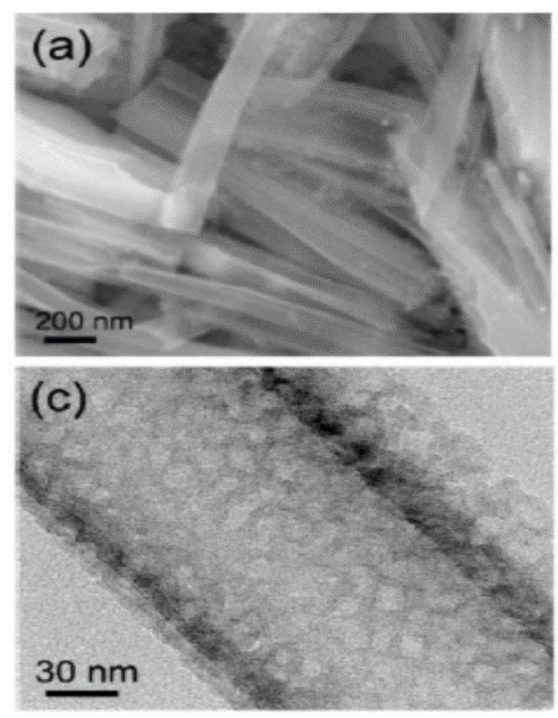
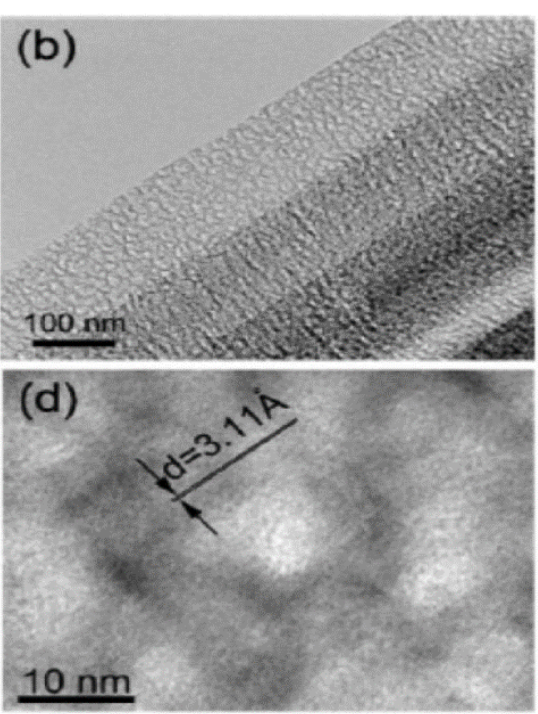

Figure 5. (a) SEM and (b) TEM images of porous Si nanowires; (c,d) High-resolution transmission electron microscopy (HRTEM) image of a nanowire in (b), leading to the results in Figure 4. Reproduced with permission from [32]. Copyright Wiley, 2012. 


\subsection{Porous $\mathrm{Si}$}

As already said, on one hand the porosity reduces the stress by providing additional free space for volume expansion induced by lithium-ion insertion, and another hand nanowires are not necessarily the best shape of nanostructured silicon. Different porous silicon anodes with pores of several nanometers or hollow silicon spheres with a thin shell have also been synthesized [66,71-75]. The pores are easily obtained by boron doping (p-type doping, while the phosphor doping mentioned earlier is n-type doping). The formation of holes in the silicon were insured by boron, which provides defective sites facilitating the etching process. This way, the structure obtained combined both properties needed to optimize the electrochemical properties: doping plus porosity. This is the procedure used, for instance, to synthesize the porous doped Nws [32] in the previous section. We have just pointed out the need for a more scalable method to prepare nano-Si. One solution has been to start with commercial silicon nanoparticles available in large quantity as starting material [76]. Such porous silicon nanoparticles after graphene wrapping delivered capacity is $2500 \mathrm{mAh} \cdot \mathrm{g}^{-1}$ at $C / 8$ rate, and $1000 \mathrm{mAh} \cdot \mathrm{g}^{-1}$ at $C / 2$ rate, and the capacity remained at $1400 \mathrm{mAh} \cdot \mathrm{g}^{-1}$ and $1000 \mathrm{mAh} \cdot \mathrm{g}^{-1}$ after 200 cycles at $C / 4$ and $C / 2$ rate, respectively. In another work, a capacity of $2000 \mathrm{mAh} \cdot \mathrm{g}^{-1}$ for 50 cycles has been obtained with pore size of several hundred nanometers [77]. Comparable results have been obtained with porous silicon prepared by electrochemical etching with a HF etching solution [78,79]. The porosity and depth of porous Si in that case are monitored by the control of the current density and the HF concentration. The porous Si can be combined with a binder such as PAN to form a slurry self-adapting to a roll-to-roll process for mass production [80].

Porous $\mathrm{Si}$ can also be obtained by $\mathrm{Si}$ deposition into a porous template. Usually, $\mathrm{SiO}_{2}$ nano-spheres are used to form an opal structure. Then, porous Si can be obtained in the form of an inverse structure by filling the voids of the template. The synthesis can be carried out through CVD gas source. The results are promising [71,81-83], but, as we have already noted, the CVD process is not suitable for industrial scale. Instead of the CVD method, the void space of the template can be filled with the gel-like silicon precursor then heat treatment at high temperature to solidify the gel forming rigid porous silicon [66]. The product demonstrated capacity retention as high as $90 \%$ at $1 C$ rate after 100 cycles.

Instead of filling the void space of the template to get an inverse porous structure, it is also possible to convert the porous silica template into silicon directly by magnesio-thermic reduction. After carbon coating by CVD process, a three-dimensional mesoporous silicon with a high surface of $74.2 \mathrm{~m}^{2} \cdot \mathrm{g}^{-1}$ obtained by this process [83]. The first reversible capacity at current density $100 \mathrm{~mA} \cdot \mathrm{g}^{-1}$ was $1956 \mathrm{~mA} \mathrm{~h} \cdot \mathrm{g}^{-1}$ ( $3104 \mathrm{~mA} \mathrm{~h} \cdot \mathrm{g}^{-1}$ when the mass of carbon is excluded) decreasing to $973 \mathrm{~mA} \mathrm{~h} \cdot \mathrm{g}^{-1}$ after 50 cycles.

The conducting carbon is expected to increase the electrical conductivity, since the electrons reaching the surface of a Si-particle can be driven to the current collector via the carbon, provided the carbon network percolates through the structure. The same goal can also be achieved by depositing amorphous Si directly onto electrode structure. An anode prepared in this way delivered a charge capacity of $1200 \mathrm{mAh} \cdot \mathrm{g}^{-1}$ stable over 120 cycles [84]. 


\subsection{Coated Si Nanostructures and Stabilization of the SEI}

The large volume changes upon cycling imply that the SEI can be broken as the nanostructure shrinks during delithiation. This re-exposes the fresh Si surface to the electrolyte and more SEI forms, resulting in a thicker and thicker SEI film upon charge/discharge cycling and, thus, aging [85]. Stabilizing the SEI is thus crucial. This is partly done by the appropriate choice of the binder. The best one for Si-anodes is alginate which is helpful in building a deformable and stable SEI [86]. In addition, coating the silicon structure with a protective element helps in the formation of a stable SEI layer [87,88]. A thick shell is preferred to avert fracture of the nanoparticles, but a thin shell reduces the loss of weight. Therefore, careful engineering of the core and shell materials is required to obtain an optimal balance, not only to optimize (and thus control) the thickness of the shell, but also the choice of the material that must have the appropriate Young's modulus [89,90].

The traditional process for any active material used in Li-ion batteries, whether it is used on the cathode or the anode side, is to coat the particles with conductive carbon. The same was tried with $\mathrm{Si}$ particles. Si-C composite particles in which silicon nanoparticles are embedded in porous carbon particles [91] and porous Si-C composite nanospheres [92] were synthesized. A successful control of the SEI growth of porous nanotubes was obtained by coating them with rigid carbon [93]. Embedding Si nanowires in a network of carbon nanotubes is also a way to improve the conductivity to improve the overall electric conductivity of the anode; moreover, the resulting anode is flexible and self-standing [94]. In [95], Si nanoparticles were completely sealed inside thin, self-supporting carbon shells, with void space in between the particles and the shells. Due to the well-defined void space, the Si particles can expand freely without breaking the outer carbon shell that stabilize the SEI on the shell surface. This yolk-shell structured Si electrode exhibits high capacity $\left(2800 \mathrm{mAh} \cdot \mathrm{g}^{-1}\right.$ at $\left.C / 10\right)$, long cycle life (1000 cycles with $74 \%$ capacity retention), and high coulombic efficiency (99.84\%). With $10 \mathrm{~nm}$ thick carbon coating on Si nanowires of $90 \mathrm{~nm}$ in diameter, the first cycle coulombic efficiency was greatly enhanced from $70 \%$ (without coating) to $83 \%$, in addition to the increased capacity from $3125 \mathrm{mAh} \cdot \mathrm{g}^{-1}$ (without coating) to $3702 \mathrm{mAh} \cdot \mathrm{g}^{-1}$, and cycling stability (5\% capacity retention after 15 cycles) [96]. However, replacing the carbon coating with $10 \mathrm{~nm}$ thick $\mathrm{Cu}$ film can further improve the coulombic efficiency of the initial cycle up to $90.3 \%$, and improve capacity retention up to $86 \%$ after 15 cycles [97]. We have already mentioned the results obtained on a Si-C nanocomposite in [83], but in this work too, the coating with $\mathrm{Cu}$ gives better results (Figure 6). These results illustrate that the traditional slurry coating method exploiting conductive carbon may not be best in the case of Si nanoparticles. To explain this result, one can invoke the fact that $\mathrm{Cu}$ is more conductive than carbon; it is also possible that the $\mathrm{Cu}$ coat is more protective and stabilizes the SEI more efficiently. In any case, this has been the motivation for trying different coats. In particular, Al-coating proved to be efficient to obtain a more stable mechanical structure of electrodes [98,99]. Si nanowires coated with $a \approx 100 \mathrm{~nm}$ layer of $\mathrm{Ag} / \mathrm{poly}(3,4-$ ethylenedioxythiophene) (PEDOT) exhibited an improvement of the capacity retention from $30 \%$ after few cycles, to $80 \%$ after 100 cycles, with respect to the same wires before coating [100]. These coats have in common the fact that they are metallic, i.e., conducting. However, $\mathrm{Al}_{2} \mathrm{O}_{3}$ coatings $(<10 \mathrm{~nm})$ obtained by ALD have been tested successfully on Si thin films [101,102] and Si Nws [103]. Upon the first lithiation, $\mathrm{Al}_{2} \mathrm{O}_{3}$ transforms into an Al-Li-O glass [104], which is a good ionic conductor and an electronic insulator, thus exhibiting the attributes of a good SEI substitute. Indeed, the $\mathrm{Al}_{2} \mathrm{O}_{3}$ coating 
resulted in a $45 \%$ increase of the anode lifetime, and 1280 cycles at $1 C$ have been obtained with $\mathrm{Al}_{2} \mathrm{O}_{3}$ coated Si Nws [103]. Double walled Si nanotubes have been obtained by coating the Si nanotube with $\mathrm{SiO}_{x}$ [105]. This coat is rigid enough and mechanically strong, so that it can successfully prevent the $\mathrm{Si}$ from expanding outward during lithiation, while still allowing lithium ions to pass through. As a result, the $\mathrm{SiO}_{x}$-coated Si nanotubes in [93] demonstrated a long cycle life (6000 cycles with $88 \%$ capacity retention), high capacity $\left(2970 \mathrm{mAh} \cdot \mathrm{g}^{-1}\right.$ at $C / 5 ; 1000 \mathrm{mAh} \cdot \mathrm{g}^{-1}$ at $\left.12 \mathrm{C}\right)$, and fast charging/discharging rates (up to $20 \mathrm{C}$ ). This result shows that it is now possible to obtain Si anodes with high capacity and good capacity retention for thousands of cycles at the laboratory scale.
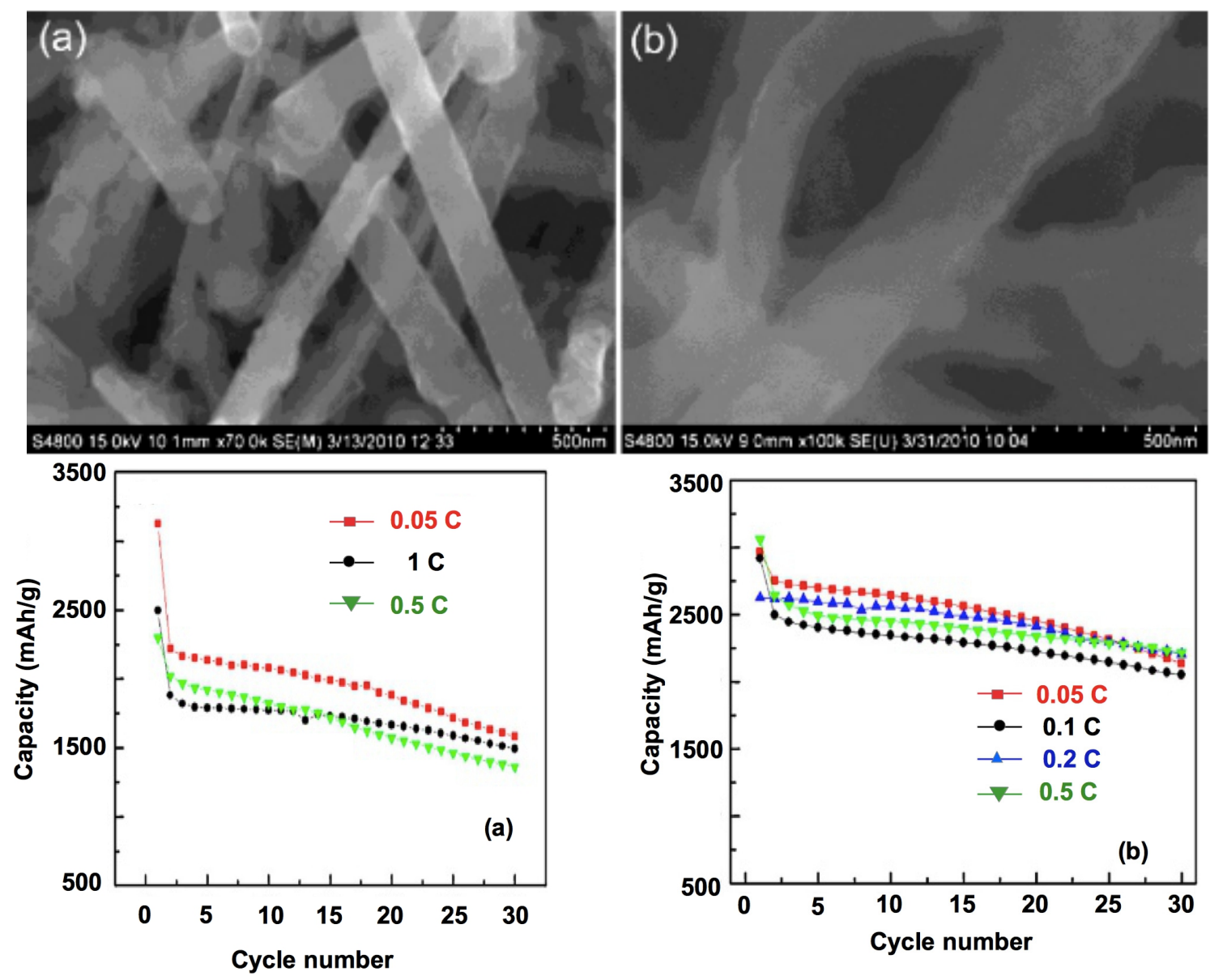

Figure 6. Top: SEM images of the silicon nanowires ( $\mathrm{Si} \mathrm{Nws)}$ (a) with and (b) without copper-coating after 100 cycles at the rate of $0.5 C$; Bottom: capacity-cycle number curves for Si nanowires (a) without and (b) with copper-coating at different rates. Reproduced with permission from [97]. Copyright Elsevier, 2011.

However, the cost of the synthesis processes is still a limiting factor for large size battery applications. The process described in [105] using vertically aligned carbon nanotubes (VACNTs) uniformly coated with $\mathrm{Si}$ and a thin $\mathrm{C}$ surface layer is a scalable method to produce ultra-thick, yet highly conductive and stable, Li-ion battery electrodes. Such an anode demonstrated very good stability for over 250 cycles and high specific capacity approaching theoretical limits $\left(4200 \mathrm{mAh} \cdot \mathrm{g}^{-1}\right)$. Recently, a robust method to prepare gram-scale Si NTs has been reported using nanorod-like nickel-hydrazine complexes as templates [106]. These different results show that the efforts currently done to find scalable synthesis 
processes without altering the electrochemical performance of Si anodes open the route to their mass production in the near future.

\section{4. $\mathrm{Li}_{4} \mathrm{Ti}_{5} \mathrm{O}_{12}$}

The $\mathrm{Li}_{4} \mathrm{Ti}_{5} \mathrm{O}_{12}$ (LTO) spinel is now considered as a viable anode for Li-ion batteries. It exhibits excellent Li-ion reversibility according to a two-phase reaction maintaining the constant voltage at $1.55 \mathrm{~V} v s . \mathrm{Li}^{0} / \mathrm{Li}^{+}$. Of course, this rather high voltage reduces by $1.2 \mathrm{~V}$ the operational potential with a cell equipped with a classical carbon anode, and this means a reduction of energy density. On the other hand, this drawback is compensated by other advantages. The SEI forms on the anodes, whether they are carbon, graphite, or metal oxides, as soon as the voltage is lower than $1 \mathrm{~V}$ during Li insertion. In that case, the formation of the SEI is controlled by the reduction of the solvents present in the electrolyte, namely ethylene carbonate (EC) and diethyl carbonate (DEC), aided by the presence of the Li salt ( $\mathrm{LiPF}_{6}$ ).

The reaction at $1.55 \mathrm{~V}$ implies that no SEI is formed at the surface of LTO. Not only does it avoid the safety problems linked to the SEI with other anodes, but it also makes it possible to get rid of EC to use other electrolytes allowing the fabrication of batteries working at high temperature $80^{\circ} \mathrm{C}$ [107], or subzero temperature [108], which is not possible with other Li-ion batteries. It is cheap, very safe, environmental friendly, and has a remarkable structural stability. In addition, Li cycling involves very little change in the cubic lattice parameter so that LTO is a "zero strain" material, resulting in a much longer cycling life. LTO is, thus, ideally suited as an anode material. That is why a large number of papers have been devoted to this material, reviewed in [2,109-111].

Like in the case of Si, however, the electrical conductivity of LTO is small, and this problem can be solved owing to the same remedy: use nano-structured LTO, eventually carbon coated, and preferentially porous, to increase the effective surface area with the electrolyte. For instance, porous LTO crystallites with a surface area of $12 \mathrm{~m}^{2} \cdot \mathrm{g}^{-1}$, of varying size between 20 and $50 \mathrm{~nm}$, delivered a capacity value close to the theoretical value of $175 \mathrm{mAh} \cdot \mathrm{g}^{-1}$ at $C / 2$ rate, and 140 and $70 \mathrm{mAh} \cdot \mathrm{g}^{-1}$ at $10 C$ and $100 C$ discharge rates, respectively, without significant aging over 100 cycles as shown in Figures 7 and 8 [112]. Mesoporous nest-like LTO with large surface area $219.2 \mathrm{~m}^{2} \cdot \mathrm{g}^{-1}$ delivered $113.6 \mathrm{mAh} \cdot \mathrm{g}^{-1}$ were obtained at $57 C$ [113]. $10 \mathrm{~nm}$-thick nano flower-like LTO delivered $118 \mathrm{mAh} \cdot \mathrm{g}^{-1}$ at $30 C$ [114]. These examples show that LTO nanoparticles of different morphologies are performing even at a high $C$-rate.

To obtain even better results, nano-LTO (nano-rods, hollow spheres, nanoparticles) has been carbon-coated [107,115,116]. C-LTO nanoparticles with $90 \mathrm{~nm}$ in size showed a capacity of $166 \mathrm{mAh} \cdot \mathrm{g}^{-1}$ at $C / 24$, remaining larger than $150 \mathrm{mAh} \cdot \mathrm{g}^{-1}$ at $40 C$-rate [107]. LTO consisting in $0.5-1 \mu \mathrm{m}$ sized porous microspheres composed of $11 \mathrm{~nm}$-sized crystallites (pore diameter $4.3 \mathrm{~nm}$ ) delivered 158 and $100 \mathrm{mAh} \cdot \mathrm{g}^{-1}$ at $1 C$ and $50 C$, respectively without noticeable capacity fading [117]. LTO nano-platelets of size 10-20 nm uniformly dispersed on reduced graphite oxide (RGO) to form a nano-hybrid composite delivering a capacity of $101 \mathrm{mAh} \cdot \mathrm{g}^{-1}$ at $100 C$ rate [118]. 

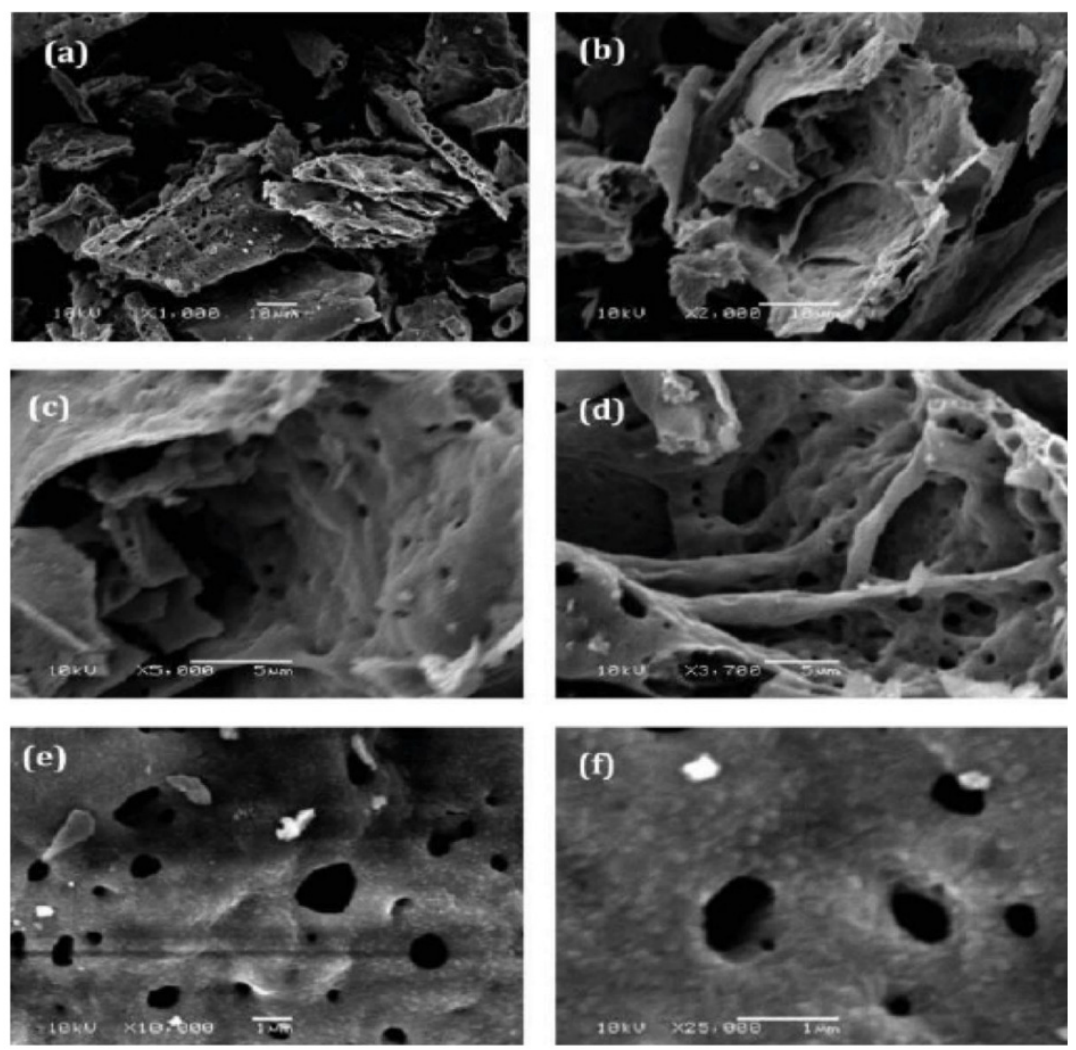

Figure 7. SEM images for nanocrystalline $\mathrm{Li}_{4} \mathrm{Ti}_{5} \mathrm{O}_{12}$ at different magnifications synthesized by combustion method. Reproduced with permission from [110]. Copyright American Chemical Society, 2013.

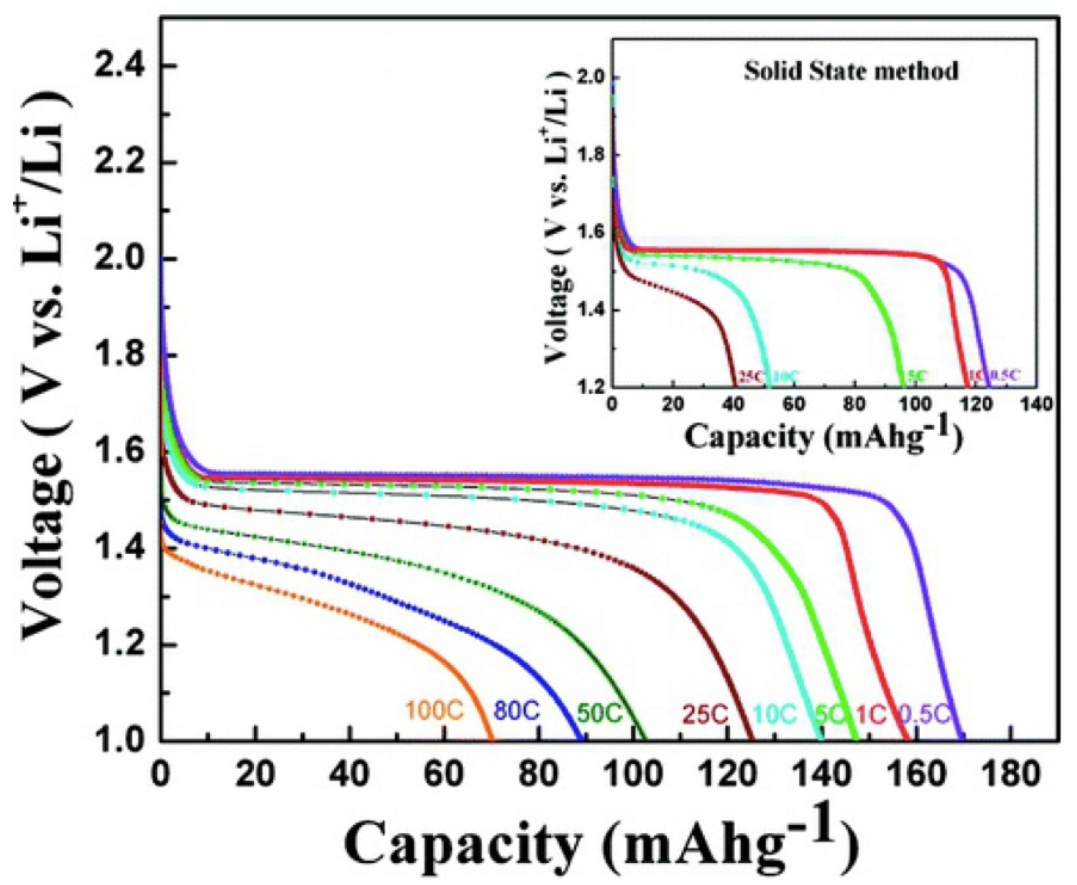

Figure 8. Capacity-voltage profile for nanocrystalline $\mathrm{Li}_{4} \mathrm{Ti}_{5} \mathrm{O}_{12}$ (SEM images in Figure 7) synthesized by the combustion method at different $C$-rates. Inset shows capacity voltage profile for bulk $\mathrm{Li}_{4} \mathrm{Ti}_{5} \mathrm{O}_{12}$ prepared by the solid-state method. Reproduced with permission from [108]. Copyright Elsevier, 2014. 
The tests on the electrodes of Li-ion batteries are always made on half-cells, i.e., with lithium metal as counter-electrode. Due to advantages of LTO over graphite anodes, full lithium-ion batteries with LTO anodes and different cathodes have also been tested. LTO has first been associated with $\mathrm{LiMn}_{2} \mathrm{O}_{4}$ spinel $[119,120]$. High-power capabilities of nano-LTO/ $\mathrm{LiMn}_{2} \mathrm{O}_{4}$ batteries, using $20 \mathrm{~nm}$ LTO with fast charge capability up to $80 C$ over 1000 cycles has been reported [121]. Nano-LTO/ $\mathrm{LiMn}_{2} \mathrm{O}_{4}$ cells with micrometer size $(0.5-2 \mu \mathrm{m})$ secondary particles composed of nanosize $(\leq 10 \mathrm{~nm})$ primary particles LTO as the anode and spherical particles of $\mathrm{LiMn}_{2} \mathrm{O}_{4}$ as the cathode have also been constructed [122]. Nearly $100 \%$ capacity retention was reported over 1000 cycles at $5 C$ rate at $55^{\circ} \mathrm{C}$ together with excellent performance at low temperature $\left(-30^{\circ} \mathrm{C}\right)$. These performances make such a cell suitable for HEVs and energy-storage for electric grids. LTO has also been associated with lamellar compounds as the counter-electrode [120,123-125].

Outstanding results have been obtained with $\mathrm{LiFePO}_{4}$ as the cathode. Capacities of 155 and $122 \mathrm{~mA}$ $\mathrm{h} \cdot \mathrm{g}^{-1}$ at $0.1 C$ and $5 C$ rates with nanoscale $\mathrm{LTO}^{\mathrm{L}} \mathrm{LiFePO}_{4}$ [126]. The size of the LTO particles ranged from 50 to $200 \mathrm{~nm}$, while the $\mathrm{LiFePO}_{4}$ particles of size $50-100 \mathrm{~nm}$ were coated with $2-4 \mathrm{~nm}$ thick carbon. A safe and fast-charging LIB with long shelf life for power applications used LTO (150 nm particle size) as anode and $2 \mathrm{wt} \%$ carbon- coated nano-LiFePO (particle size: $25 \mathrm{~nm}$ ) as cathode [127]. Full capacity after 20000 cycles performed at charge rate of $10 C$ and discharge rate of $5 C$, and retained $95 \%$ of the capacity after 30000 cycles at charge rate $15 C$ and discharge rate $1 C$, both at $100 \%$ depth of discharge) and $100 \%$ state of charge. Even higher powers have been obtained by coating these LTO particles with carbon [105].

\section{Conclusions}

The nanotechnology and its application to the synthesis of nano-structured electrodes is the key of the progress that has been currently made on lithium-ion batteries. In the case of positive electrodes, this nanotechnology opens the route to the replacement of the graphite. Different batteries have been tested, especially employing Nano-sized $\mathrm{Li}_{4} \mathrm{~T}_{5} \mathrm{O}_{12}$. They showed outstanding performance regarding the $C$-rate capability, cycling stability, calendar life, pulse-power characteristics, and abuse tolerance. Such anodes should now be developed over the next years for many applications. Silicon is very promising for its very large theoretical capacity, some scalable synthesis processes opening the route to prepare nano-Si anodes at a reasonable price. The few examples given in this review also illustrates the large variety of morphologies that can be used, which combines with the large variety of oxides of transition metals, making the research on the materials science active and promising for years to come.

\section{Acknowledgments}

The authors gratefully acknowledge many stimulating discussions with Dr. Henri Groult (PHENIX, University Paris-6).

\section{Author Contributions}

The authors contributed equally to the reported research and writing the paper. 


\section{Conflicts of Interest}

The authors declare no conflict of interest.

\section{References}

1. Goriparti, S.; Miele, E.; De Angelis, F.; Di Fabrizio, E.; Zaccaria, R.P.; Capiglia, C. Review on recent progress of nanostructured anode materials for Li-ion batteries. J. Power Sour. 2014, 257, 421-443.

2. Julien, C.M.; Mauger, A.; Vijh, A.; Zaghib, K. Lithium Batteries: Science and Technology; Springer: Cham, Switzerland, 2015.

3. Li, C.C.; Orsini, F.; DuPasquier, A.; Beaudouin, B.; Tarascon, J.M.; Trentin, M.; Langenhuizen, N.; DeBeer, E.; Notten, P. In situ SEM study of the interfaces in plastic lithium cells. J. Power Sour. 1999, 81-82, 918-921.

4. Landi, B.J.; Ganter, M.J.; Cress, C.D.; Di Leo, R.A.; Raffaelle, R.P. Carbon nanotubes for lithium ion batteries. Energy Environ. Sci. 2009, 2, 638-654.

5. Kim, C.K.; Yang, S.; Kojima, M.; Yoshida, K.; Kim, Y.J.; Kim, Y.A.; Endo, M. Fabrication of electrospinning-derived carbon nanofiber webs for the anode material of lithium-ion secondary batteries. Adv. Funct. Mater. 2006, 16, 2393-2397.

6. Wu, Y.P.; Rahm, E; Holze, R. Carbon anode materials for lithium ion batteries. J. Power Sources 2003, 114, 228-236.

7. Cui, G.; Gu, L.; Zhi, L.; Kaskhedikar, N.; Aken, P.A.; Mullen, K.; Maier, J. A germanium-carbon nanocomposite material for lithium batteries. Adv. Mater. 2008, 20, 3079-3083.

8. Candelaria, S.L.; Shao, Y.; Zhou, W.; Li, X.; Xiao, J.; Zhang, J.-G.; Wang, Y.; Liu, J. Li, J.; Cao, G. Nanostructured carbon for energy storage and conversion. Nano Energy 2012, 1, 195-220.

9. Liu, Y.; Xue, J.S.; Zheng, T.; Dahn, J.R. Mechanism of lithium insertion in hard carbons prepared by pyrolysis of epoxy resins. Carbon 1996, 34, 193-200.

10. Mabuchi, A.; Tokumitsu, K.; Fujimoto, H.; Kasuh, T. Charge-discharge characteristics of the mesocarbon microbeads heat-treated at different temperatures. J. Electrochem. Soc. 1995, 142, 1041-1046.

11. Nagao, M.; Pitteloud, C.; Kamiyama, T.; Otomo, T.; Itoh, K.; Fukunaga, T.; Tatsumi, K.; Kanno, R. Structure characterization and lithiation mechanism of nongraphitized carbon for lithium secondary batteries. J. Electrochem. Soc. 2006, 153, A914-A919.

12. Sun, J.; Liu, H.; Chen, X.; Evans, D.G.; Yang, W.; Duan, X. Carbon nanorings and their enhanced lithium storage properties. Adv. Mater. 2013, 25, 1125-1130.

13. Meunier, V.; Kephart, J.; Roland, C.; Bernhole, J. Ab initio investigations of lithium diffusion in carbon nanotube systems. J. Phys. Rev. Lett. 2002, 88, doi:10.1103/physrevlett.88.075506.

14. Schauerman, C.M.; Ganter, M.J.; Gaustad, G.; Babbitt, C.W.; Raffaelle, R.P.; Landi, B.J. Recycling single-wall carbon nanotube anodes from lithium ion batteries. J. Mater. Chem. 2012, 22, 12008-12015.

15. Nishidate, K.; Hasegawa, M. Energetics of lithium ion adsorption on defective carbon nanotubes. Phys. Rev. B 2005, 71, 245418. 
16. Zhao, J.; Buldum, A.; Han, J.; Ping-Lu, J. First-principles study of Li-intercalated carbon nanotube ropes. Phys. Rev. Lett. 2000, 85, 1706-1709.

17. Di Leo, R.A.; Castiglia, A.; Ganter, M.J.; Rogers, R.E.; Cress, C.D.; Raffaelle, R.P.; Landi B.J. Enhanced capacity and rate capability of carbon nanotube based anodes with titanium contacts for lithium ion batteries. ACS Nano 2010, 4, 6121-6131.

18. Lahiri, I.; Oh, S.-M.; Hwang, J.Y.; Kang, C.; Choi, M.; Jeon, H.; Banerjee, R.; Sun, Y.K.; Choi, W. Ultrathin alumina-coated carbon nanotubes as an anode for high capacity Li-ion batteries. J. Mater. Chem. 2011, 21, 13621-13626.

19. Leung, K.; Qi, Y.; Zavadil, K.R.; Jung, Y.S. Dillon, A.C.; Cavanagh, A.S.; Lee, S.-H.; George, S.M. Using atomic layer deposition to hinder solvent decomposition in lithium ion batteries: First-principles modeling and experimental studies. J. Am. Chem. Soc. 2011, 133, 14741-14754.

20. Jung, Y.S.; Cavanagh, A.S.; Riley, L.A.; Kang, S.-H.; Dillon, A.C.; Groner, M.D.; George, S.M.; Lee, S.H. Ultrathin direct atomic layer deposition on composite electrodes for highly durable and safe Li-ion batteries. Adv. Mater. 2010, 22, 2172-2176.

21. Liu, Y.; Zheng, Z.; Liu, X.H.; Huang, S.; Zhu, T.; Wang, J.; Kushim, A.; Hudak, N.S.; Huang, X.; Zhang, S.; et al. Lithiation-induced embrittlement of multiwalled carbon nanotubes. ACS Nano 2011, 5, 7245-7253.

22. Wu, Z.-S.; Zhou, G.; Yin, L.-C.; Ren, W.; Li, F., Cheng, H.-M. Graphene/metal oxide composite electrode materials for energy storage. Nano Energy 2012, 1, 107-131.

23. Hou, J.; Shao, Y.; Ellis, M.W.; Moore, R.B.; Yi, B. Graphene-based electrochemical energy conversion and storage: fuel cells, supercapacitors and lithium ion batteries. Phys. Chem. Chem. Phys. 2011, 13, 15384-15402.

24. Fang, S.; Shen, L.; Zheng, H.; Zhang, X. Ge-graphene-carbon nanotube composite anode for high performance lithium-ion batteries. J. Mater. Chem. A 2015, 3, 1498-1505.

25. Liang, M.; Zhi, L. Graphene-based electrode materials for rechargeable lithium batteries. J. Mater. Chem. 2009, 19, 5871-5878.

26. Brownson, D.A.C.; Kampouris, D.K.; Banks, C.E. An overview of graphene in energy production and storage applications. J. Power Sour. 2011, 196, 4873-4885.

27. Hwang, H.Y.; Koo, J.; Park, M.; Park, N.; Kwon, Y.; Lee, H. Multilayer graphynes for lithium ion battery anode. J. Phys. Chem. C 2013, 117, 6919-6923.

28. Pan, D.; Wang, S.; Zhao, B.; Wu, M.; Zhang, H.; Wang, Y.; Jiao, Z. Li storage properties of disordered grapheme nanosheets. Chem. Mater. 2009, 21, 3136-3142.

29. Lee, S.U.; Belosludov, R.V.; Mizuseki, H.; Kawazoe, Y. Designing nanogadgetry for nanoelectric devices with nitrogen-doped capped carbon nanotubes. Small 2009, 5, 1769-1775.

30. Wang, Z.-L.; Xu, D.; Wang, H.G.; Wu, Z.; Zhang, X.-B. In situ fabrication of porous grapheme electrodes for high-performance energy storage. ACS Nano 2013, 7, 2422-2430.

31. Mahmood, N.; Zhang, C.; Liu, F.; Zhu, J.; Hou, Y. Hybrid of $\mathrm{Co}_{3} \mathrm{Sn}_{2} @$ Co nanoparticles and nitrogen-doped grapheme as a lithium battery anode. ACS Nano 2013, 7, 10307-10318.

32. Ge, M.Y.; Rong, J.; Fang, X.; Zhou, C. Porous doped silicon nanowires for lithium ion battery anode with long cycle life. Nano Lett. 2012, 12, 2318-2323. 
33. Ge, M.Y.; Lu, Y.H.; Ercius, P.; Rong, J.P.; Fang, X.; Zhou, C.W.; Mecklenburg, M. Large-scale fabrication, 3D tomography and lithium-ion battery application of porous silicon. Nano Lett. 2014, 14, 261-268.

34. Besenhard, J.O.; Yang, J.; Winter, M. Will advanced lithium-alloy anodes have a chance in lithium-ion batteries? J. Power Sour. 1997, 68, 87-90.

35. Beaulieu, L.Y.; Eberman, K.W.; Turner, R.L.; Krause, L.J.; Dahn, J.R. Collossal reversible volume changes in lithium alloys. Electrochem. Solid State Lett. 2001, 4, A137-A140.

36. Beaulieu, L.Y.; Hatchard, T.D.; Bonakdarpour, A.; Fleischauer, M.D.; Dahn, J.R. Reaction of Li with alloy thin films studied by in situ AFM. J. Electrochem. Soc. 2003, 150, A1457-A1464.

37. Zhang, X.W.; Patil, P.K.; Wang, C.S.; Appleby, A.J.; Little, F.E.; Cocke, D.L. Electrochemical performance of lithium ion battery, nano-silicon-based, disordered carbon composite anodes with different microstructures. J. Power Sour. 2004, 125, 206-213.

38. Chan, C.K.; Peng, H.L.; Liu, G.; Mcllwrath, K.; Zhang, X.F.; Huggins, R.A.; Cui, Y. High-performance lithium battery anodes using silicon nanowires. Nat. Nanotechnol. 2008, 3, 31-35.

39. McDowell, M.T.; Lee, S.W.; Wang, C.; Cui, Y. The effect of metallic coatings and crystallinity on the volume expansion of silicon during electrochemical lithiation/delithiation. Nano Energy 2012, $1,401-410$.

40. Maver, U.; Znidarsic, A.; Gaberscek, M. An attempt to use atomic force microscopy for determination of bond type in lithium battery electrodes. J. Mater. Chem. 2011, 21, 4071-4075.

41. Soni, S.K.; Sheldon, B.W.; Xiao, X.C.; Verbrugge, M.W.; Ahn, D.; Haftbaradaran, H.; Gao, H.J. Stress migration during the lithiation of patterned amorphous Si islands. J. Electrochem. Soc. 2012, 159, A38-A43.

42. Lee, K.L.; Jung, J.Y.; Lee, S.W.; Moon, H.S.; Park, J.W. Electrochemical characteristics of a-Si thin film anode for Li-ion rechargeable batteries. J. Power Sour. 2004, 129, 270-274.

43. Park, M.S.; Wang, G.X.; Liu, H.K.; Dou, S.X. Electrochemical properties of Si thin film prepared by pulse laser deposition for lithium ion microbatteries. Electrochim. Acta 2006, 51, 5246-5249.

44. Raimann, P.R.; Hochgatterer, N.S.; Korepp, C.; Moller, K.C.; Winter, M.; Schrottner, H.; Hofer, F.; Besenhard, J.O. Monitoring dynamics of electrode reactions in Li-ion batteries by in situ ESEM. Ionics 2006, 12, 253-255.

45. Kim, H.; Choi, J.; Sohn, H.J.; Kang, T. The insertion mechanism of lithium $\mathrm{Mg}_{2} \mathrm{Si}$ anode material for Li-ion batteries. J. Electrochem. Soc. 1999, 146, 4401-4405.

46. Wachtler, M.; Winter, M.; Besenhard, J.O. Anodic materials for rechargeable Li-batteries. J. Power Sour. 2002, 105, 151-160.

47. Kim, J.W.; Ryu, J.H.; Lee, K.T.; Oh, S.M. Improvement of silicon powder negative electrodes by copper electroless deposition for lithium secondary batteries. J. Power Sour. 2005, 147, 227-233.

48. Goldman, J.L.; Long, B.R.; Gewirth, A.A.; Nuzzo R.G. Strain anisotropies and self-limiting capacities in single-crystalline 3D silicon microstructures: Models for high energy density lithium-ion battery anodes. Adv. Funct. Mater. 2011, 21, 2412-2422.

49. Yang, J.; Winter, M.; Besenhard, J.O. Small particle size multiphase Li-alloy anodes for lithium-ion batteries. Solid State Ion.1996, 90, 281-287. 
50. Stjerndahl, M.; Bryngelsson, H.; Gustafsson, T.; Vaughey, J.T.; Tackeray, M.M.; Edstrom, K. Surface chemistry of intermetallic AlSb-anodes for Li-ion batteries. Electrochim. Acta 2007, 52, 4947-4955.

51. Lee, S.W.; McDowell, M.T.; Choi, J.W.; Cui, Y. Anomalous shape changes of silicon nanopillars by electrochemical lithiation. Nano Lett. 2011, 11, 3034-3039.

52. Wagesreither, S.; Lugstein, A.; Bertagnolli, E. Anisotropic lithiation behavior of crystalline silicon. Nanotechnology 2012, 23, 495716-495719.

53. Liu, X.H.; Wang, J.W.; Huang, S.; Fan, F.F.; Huang, X.; Liu, Y.; Krylyuk, S.; Yoo, J.; Dayeh, S.A.; Davydov, A.V.; et al. In situ atomic-scale imaging of electrochemical lithiation in silicon. Nat. Nanotechnol. 2012, 7, 749-756.

54. Takamura, T.; Ohara, S.; Uehara, M.; Suzuki, J.; Sekine, K. A vacuum deposited Si film having a Li extraction capacity over $2000 \mathrm{mAh} / \mathrm{g}$ with a long cycle life. J. Power Sour. 2004, 129, 96-100.

55. Ohara, S.; Suzuki, J.; Sekine, K.; Takamura, T. Li insertion/extraction reaction at a Si film evaporated on a Ni foil. J. Power Sour. 2003, 119-121, 591-596.

56. Chen, L.B.; Xie, J.Y; Yu, H.C.; Wang, T.H. An amorphous Si thin film anode with high capacity and long cycling life for lithium ion batteries. J. Appl. Electrochem. 2009, 39, 1157-1162.

57. Maranchi, J.P.; Hepps, A.F.; Evans, A.G.; Nuhfer, N.T., Kumta, P.N. Interfacial properties of the a-Si/Cu: Active-inactive thin-film anode system for lithium-ion batteries. J. Electrochem. Soc. 2006, 153, A1246-A1253.

58. Yu, C.; Li, X.; Ma, T.; Rong, J.; Zhang, R.; Shaffer, J.; An, Y.; Liu, Q.; Wei, B.; Jiang, H. Silicon thin films as anodes for high-performance lithium-ion batteries with effective stress relaxation. Adv. Energy Mater. 2012, 2, 68-73.

59. Schmidt, V.; Wittemann, J.V.; Gösele, U. Growth, thermodynamics and electrical properties of silicon nanowires. Chem. Rev. 2010, 110, 361-388.

60. Cui, L.F.; Ruffo, R.; Chan, C.K.; Peng, H.L.; Cui, Y. Crystalline-amorphous core-shell silicon nanowires for high capacity and high current battery electrodes. Nano Lett. 2009, 9, 491-495.

61. Chan, C.K.; Patel, R.N.; O'Connell, M.J.; Korgel, B.A.; Cui, Y. Solution-grown silicon nanowires for lithium-ion battery anodes. ACS Nano 2010, 4, 1443-1450.

62. Nguyen, H.T.; Yao, F.; Zamfir, M.R.; Biswas, C.; So, K.P.; Lee, Y.H.; Kim, S.M.; Cha, S.N.; Kim, J.M.; Pribat, D. Highly interconnected Si nanowires for improved stability Li-ion battery anodes. Adv. Energy Mater. 2011, 1, 1154-1161.

63. Bruce, P.G.; Scrosati, B.;Tarascon, J.M. Nanomaterials for rechargeable lithium batteries. Angew. Chem. Int. Ed. 2008, 47, 2930-2946.

64. Bang, B.M.; Kim, H.; Song, H.K.; Cho, J.; Park, S. Scalable approach to multi-dimensional bulk Si anodes via metal-assisted chemical etching. Energy Environ. Sci. 2011, 4, 5013-5019.

65. Zamfir, M.R.; Nguyen, H.T.; Moyen, E.; Lee, Y.H.; Pribat, D. Silicon nanowires for Li-based battery anodes: A review. J. Mater. Chem. A 2013, 1, 9566-9586.

66. Kim, H.; Han, B.; Choo, J.; Cho, J. Three-dimensional porous silicon particles for use in high-performance lithium secondary batteries. Angew. Chem. Int. Ed. 2008, 47, 10151-10154.

67. Kim, H.; Cho, J. Superior lithium electroactive mesoporous Si@carbon core-shell nanowires for lithium battery anode material. Nano Lett. 2008, 8, 3688-3691. 
68. Song, T.; Cheng, H.Y.; Choi, H.; Lee, J.H.; Han, H.; Lee, D.H.; Yoo, D.S.; Kwon, M.S.; Choi, J.M.; Doo, S.G.; et al. Si/Ge double-layered nanotube array as a lithium ion battery anode. ACS Nano 2012, 6, 303-309.

69. Song, T.; Xia, J.L.; Lee, J.H.; Lee, D.H.; Kwon, M.S.; Choi, J.M.; Wu, J.; Doo, S.K.; Chang, H.; Park, W.; et al. Arrays of sealed silicon nanotubes as anodes for lithium ion batteries. Nano Lett. 2010, 10, 1710-1716.

70. Park, M.H.; Kim, M.G.; Joo, J.; Kim, K.; Kim, J.; Ahn, S.; Cui, Y.; Cho, J. Silicon nanotube battery anodes. Nano Lett. 2009, 9, 3844-3847.

71. Yao, Y.; McDowell, M.T.; Ryu, I.; Wu, H.; Liu, N.; Hu, L.; Nix, W.D.; Cui, Y. Interconnected silicon hollow nanospheres for lithium-ion battery anodes with long cycle life. Nano Lett. 2011, $11,2949-2954$.

72. Wang, X.L.; Han, W.Q. Graphene enhances Li storage capacity of porous sigle-crystalline silicon nanowires. ACS Appl. Mater. Int. 2010, 2, 3709-3713.

73. Rong, J.; Masarapu, C.; Ni, J.; Zhang, Z.; Wei, B. Tandem structure of porous silicon film on single-walled carbon nanotube macrofilms for lithium-ion battery applications. ACS Nano $\mathbf{2 0 1 0}$, 4, 4683-4690.

74. Guo, J.; Sun, A.; Wang, C. A porous silicon-carbon anode with high overall capacity on carbon fiber current collector. Electrochem. Commun. 2010, 12, 981-984.

75. Ma, H.; Cheng, F.Y; Chen, J.; Zhao, J.Z.; Li, C.S.; Tao, Z.L.; Liang, J. Nest-like silicon nanospheres for high-capacity lithium storage. Adv. Mater. 2007, 19, 4067-4070.

76. Ge, M.; Rong, J.; Fang, X.; Zhang, A.; Lu, Y.; Zhou, C. Scalable preparation of porous silicon nanoparticles and their application for lithium battery anodes. Nano Res. 2013, 6, 174-181.

77. Bang, B.M.; Lee, J.I.; Kim, H. Cho, J.; Park, S. High-performance macroporous bulk silicon anodes synthesized by template-free chemical etching. Adv. Energy Mater. 2012, 2, 878-883.

78. Thakur, M.; Pernites, R.B.; Nitta, N.; Isaacson, M.; Sinsabaugh, S.L.; Wong, M.S. Biswal, S.L. Freestanding macroporous silicon and pyrolyzed polyacrylonitrile as a composite anode for lithium ion batteries. Chem. Mater. 2012, 24, 2998-3003.

79. Thakur, M.; Isaacson, M.; Sinsabaugh, S.L.; Wong, M.S.; Biswal, S.L. Gold-coated porous silicon films as anodes for lithium ion batteries. J. Power Sour. 2012, 205, 426-432.

80. Thakur, M.; Sinsabaugh, S.L.; Isaacson, M.J.; Wong, M.S.; Biswal, S.L. Inexpensive method for producing macroporous silicon particulates (MPSPs) with pyrolyzed polyacrylonitrile for lithium ion batteries. Sci. Rep. 2012, 2, doi:10.1038/srep00795.

81. Zhang, H.G. Braun, P.V. Three-dimensional metal scaffold supported bicontinuous silicon battery anodes. Nano Lett. 2012, 12, 2778-2783.

82. Gowda, S.R.; Pushparaj, V.; Herle, S.; Girishkumar, G.; Gordon, J.G.; Gullapalli, H.; Zhan, X.B.; Ajayan, P.M.; Reddy, A.L.M. Three-dimensionally engineered porous silicon electrodes for Li ion batteries. Nano Lett. 2012, 12, 6060-6065.

83. Xie, J.; Wang, G.; Huo, Y.; Zhang, S.; Cao, G.; Zhao, X. Hollow nano silicon prepared by a controlled template direction and magnesiothermic reduction reaction as anode for lithium ion batteries. New J. Chem. 2014, 38, 4177-4181.

84. Cui, L.-F.; Hu, L.B.; Wu, H.; Choi, J.W.; Cui, Y. Inorganic glue enabling high performance of silicon particles as lithium ion battery anode. J. Electrochem. Soc. 2011, 158, A592-A596. 
85. Nadimpalli, S.P.; Sethuraman, V.A.; Dalavi, S.; Lucht, B.; Chon, M.J.; Shenoy, V.B.; Guduru, P.R. Quantifying capacity loss due to solid-electrolyte-interphase layer formation on silicon negative electrodes in lithium-ion batteries. J. Power Sour. 2012, 215, 145-151.

86. Kovalenko, I.; Zdyrko, B.; Magasinski, A.; Hertzberg, B.; Milicev, Z.; Burtovyy, R.; Luzinov, I.; Yushin, G. A major constituent of brown algae for use in high-capacity Li-ion batteries. Science 2011, 334, 75-79.

87. Sethuraman, V.A.; Kowolik, K.; Srinivasan, V. Increased cycling efficiency and rate capability of copper-coated silicon anodes in lithium-ion batteries. J. Power Sour. 2011, 196, 393-398.

88. Zhou, X.Y.; Tang, J.J.; Yang, J.; Xie, J.; Ma, L.L. Silicon@carbon hollow core-shell heterostructures novel anode materials for lithium ion batteries. Electrochim. Acta 2013, 87, 663-668.

89. Chen, S.; Gordin, M.L.; Yi, R.; Howlett, G.; Sohn, H.; Wang, D. Silicon core-hollow carbon shell nanocomposites with tunable buffer voids for high capacity anodes of lithium-ion batteries. Phys. Chem. Chem. Phys. 2012, 14, 12741-12745.

90. Li, X.; Meduri, P.; Chen, X.; Qi, W.; Engelhard, M.H.; Xu, W.; Ding, F.; Xiao, J.; Wang, W.; Wang, C. Hollow core-shell structured porous Si-C nanocomposites for Li-ion battery anodes. J. Mater. Chem. 2012, 22, 11014-11017.

91. Jung, D.S.; Hwang, T.H.; Park, S.B.; Choi, J.W. Spray drying method for large-scale and high-performance silicon negative electrodes in Li-ion batteries. Nano Lett. 2013, 13, 2092-2097.

92. Magasinski, A.; Dixon, P.; Hertzberg, B.; Kvit, A.; Ayala, J.; Yushin, G. High-performance lithium-ion anodes using a hierarchical bottom-up approach. Nat. Mater. 2010, 9, 353-358.

93. Wu, H.; Chan, G.; Choi, J.W.; Ryu, I.; Yao, Y.; McDowell, M.T.; Lee, S.W.; Jackson, A.; Yang, Y.; $\mathrm{Hu}$, L.B.; et al. Stable cycling of double-walled silicon nanotube battery anodes through solid-electrolyte interphase control. Nat. Nanotechnol. 2012, 7, 310-315.

94. Nyholm, L.; Nyström, G.; Mihranyan, A.; Stromme, M. Toward flexible polymer and paper-based energy storage devices. Adv. Mater. 2011, 23, 3751-3769.

95. Liu, N.; Wu, H.; McDowell, M.T.; Yao, Y.; Wang, C.; Cui, Y. A yolk-shell design for stabilized and scalable Li-ion battery alloy anodes. Nano Lett. 2012, 12, 3315-3322.

96. Chen, H.X.; Dong, Z.X.; Fu, Y.P.; Yang, Y. Silicon nanowires with and without carbon coating as anode materials for lithium-ion batteries. J. Solid State Electrochem. 2010, 14, 1829-1834.

97. Chen, H.; Xiao, Y.; Wang, L.; Yang, Y. Silicon nanowires coated with copper layer as anode materials for lithium-ion batteries. J. Power Sour. 2011, 196, 6657-6662.

98. Ryu, I.; Choi, J.W.; Cui, Y.; Nix, W.D. Size-dependent fracture of Si nanowire battery anodes. J. Mech. Phys. Solids 2011, 59, 1717-1730.

99. Liu, X.H.; Zheng, H.; Zhong, L.; Huang, S.; Karki, K.; Zhang, L.Q.; Liu, Y.; Kushima, A.; Liang, W.T.; Wang, J.W.; et al. Anisotropic swelling and fracture of silicon nanowires during lithiation. Nano Lett. 2011, 11, 3312-3318.

100. Yao, Y.; Liu, N.; McDowell, M.T.; Pasta, M.; Cui, Y. Improving the cycling stability of silicon nanowire anodes with conducting polymer coatings. Energy Environ. Sci. 2012, 5, 7927-7930.

101. Xiao, X.; Lu, P.; Ahn, D. Ultrathin multifunctional oxide coatings for lithium ion batteries. $A d v$. Mater. 2011, 23, 3911-3915.

102. He, Y.; Yu, X.; Wang, Y.; Li, H.; Huang, X. Alumina-coated patterned amorphous silicon as the anode for a lithium-ion battery with high coulombic efficiency. Adv. Mater. 2011, 23, 4938-4941. 
103. Nguyen, H.T.; Zamfir, M.R.; Duong, L.D.; Lee, Y.H.; Bondavalli, P.; Pribat, D. Alumina-coated silicon-based nanowire arrays for high quality Li-ion battery anodes. J. Mater. Chem. 2012, 22, 24618-24626.

104. Liu, Y.; Hudak, N.S.; Huber, D.L.; Limmer, S.J.; Sullivan, J.P.; Huang, J.Y. In situ transmission electron microscopy observation of pulverization of aluminum nanowires and evolution of the thin surface $\mathrm{Al}_{2} \mathrm{O}_{3}$ layers during lithiation-delithiation cycles. Nano Lett. 2011, 11, 4188-4194.

105. Evanoff, K.; Kahn, J.; Balandin, A.; Magasinski, A.; Ready, W.J.; Fuller, T.F.; Yushin, G. Towards ultrathick battery electrodes: Aligned carbon nanotube enabled architecture. Adv. Mater. 2012, 24, $533-537$.

106. Wen, Z.; Lu, G.; Mao, S.; Kim, H.; Cui, S.; Yu, K.; Huang, X.; Hurle, P.T.; Mao, O.; Chen, J. Silicon nanotube anode for lithium-ion batteries. Electrochem. Commun. 2013, 29, 67-70.

107. Zaghib, K.; Dontigny, M.; Guerfi, A.; Trottier, J.; Hamel-Paquet, J.; Gariepy, V.; Galoutov, K.; Hovington, P.; Mauger, A.; Groult, H.; et al. An improved high-power battery with increased thermal operating range: C-LiFePO $4 / / \mathrm{C}_{-} \mathrm{Li}_{4} \mathrm{Ti}_{5} \mathrm{O}_{12}$. J. Power Sour. 2012, 216, 192-200.

108. Zaghib, K.; Dontigny, M.; Perret, P.; Guerfi, A.; Ramanathan, M.; Prakash, J.; Mauger, A.; Julien, C.M. Electrochemical and thermal characterization of lithium titanate spinel in C-LiFePO $4 / / \mathrm{C}-\mathrm{Li}_{4} \mathrm{Ti}_{5} \mathrm{O}_{12}$ cells at sub-zero temperatures. J. Power Sour. 2014, 248, 1050-1057.

109. Yi, T.F.; Jiang, L.J.; Shu, J.; Yue, C.B.; Zhu, R.S.; Qiao, H.B. Recent development and application of $\mathrm{Li}_{4} \mathrm{Ti}_{5} \mathrm{O}_{12}$ as anode material of lithium ion battery. J. Phys. Chem. Solids 2010, 71, 1236-1242.

110. Reddy, M.V.; Subba Rao, G.V.; Chowdari, B.V.R. Metal oxides and oxysalts as anode materials for Li ion batteries. Chem. Rev. 2013, 113, 5364-5457.

111. Yang, Z.G.; Choi, D.; Kerisit, S.; Rosso, K.M.; Wang, D.H.; Zhang, J.; Graff, G.; Liu, J. Nanostructures and lithium electrochemical reactivity of lithium titanites and titanium oxides: A review. J. Power Sour. 2009, 192, 588-598.

112. Prakash, A.S.; Manikandan, P.; Ramesha, K.; Sathiya, M.; Tarascon, J.M.; Shukla, A.K. Solution-combustion synthesized nanocrystalline $\mathrm{Li}_{4} \mathrm{Ti}_{5} \mathrm{O}_{12}$ as high-rate performance Li-ion battery anode. Chem. Mater. 2010, 22, 2857-2863.

113. Chen, J.Z.; Yang, L.; Fang, S.H.; Hirano, S.; Tachibana, K. Synthesis of hierarchical mesoporous nest-like $\mathrm{Li}_{4} \mathrm{Ti}_{5} \mathrm{O}_{12}$ for high-rate lithium ion batteries. J. Power Sour. 2012, 200, 59-66.

114. Lin, Y.S.; Tsai, M.C.; Duh, J.G. Self-assembled synthesis of nanoflower-like Li4Tis $\mathrm{O}_{12}$ for ultrahigh rate lithium-ion batteries. J. Power Sour. 2012, 214, 314-318.

115. Cheng, L.; Yan, J.; Zhu, G.-N.; Luo, J.Y.; Wang, C.X.; Xia, Y.Y. General synthesis of carbon-coated nanostructure $\mathrm{Li}_{4} \mathrm{Ti}_{5} \mathrm{O}_{12}$ as a high rate electrode material for $\mathrm{Li}$-ion intercalation. J. Mat. Chem. 2010, 20, 595-602.

116. Zhu, G.N.; Liu, H.J.; Zhang, J.H.; Wang C.X.; Wang, Y.G.; Xia, Y.Y. Carbon-coated nano-sized $\mathrm{Li}_{4} \mathrm{Ti}_{5} \mathrm{O}_{12}$ nanoporous micro-sphere as anode material for high-rate lithium-ion batteries. Energy Environ. Sci. 2011, 4, 4016-4022.

117. Shen, L.; Yuan, C.; Luo, H.; Zhang, X.; Chen, L.; Li, H. Facile synthesis of hierarchically porous $\mathrm{Li}_{4} \mathrm{Ti}_{5} \mathrm{O}_{12}$ microspheres for high rate lithium ion batteries. J. Mater. Chem. 2010, 20, 6998-7004.

118. Kim, H.K.; Bak, S.M.; Kim, K.B. Li4 $\mathrm{Ti}_{5} \mathrm{O}_{12} /$ reduced graphite oxide nano-hybrid material for high rate lithium-ion batteries. Electrochem. Commun. 2010, 12, 1768-1771. 
119. Ariyoshi, K.; Yamamoto, S.; Ohzuku, T. Three-volt lithium-ion battery with $\mathrm{Li}\left[\mathrm{Ni}_{1 / 2} \mathrm{Mn}_{3 / 2}\right] \mathrm{O}_{4}$ and the zero-strain insertion material of $\mathrm{Li}\left[\mathrm{Li}_{1 / 3} \mathrm{Ti}_{5 / 3}\right] \mathrm{O}_{4}$. J. Power Sour. 2003, 119, 959-963.

120. Ariyoshi, K.; Ohzuku, T. Conceptual design for $12 \mathrm{~V}$ "lead-free" accumulators for automobile and stationary applications. J. Power Sour. 2007, 174, 1258-1262.

121. Du Pasquier, A.; Huang, C.C.; Spitler, T. Nano $\mathrm{Li}_{4} \mathrm{Ti}_{5} \mathrm{O}_{12}-\mathrm{LiMn}_{2} \mathrm{O}_{4}$ batteries with high power capacity and improved cycle-life. J. Power Sour. 2009, 186, 508-514.

122. Amine, K.; Belharouak, I.; Chen, Z.H.; Tran, T.; Yumoto, H.; Ota, N.; Myung, S.T.; Sun, Y.K. Nanostructured anode material for high-power battery system in electric vehicles. Adv. Mater. 2010, 22, 3052-3057.

123. Jansen, A.N.; Kahaian, A.J.; Kepler, K.D.; Nelson, P.A.; Amine, K. Dees, D.W.; Vissers, D.R.; Thackeray, M.M. Development of a high-power lithium-ion battery. J. Power Sour. 1999, 81-82, 902-905.

124. Sawai, K.; Yamato, R.; Ohzuku, T. Impedance measurements on lithium-ion battery consisting of $\mathrm{Li}\left[\mathrm{Li}_{1 / 3} \mathrm{Ti}_{5 / 3}\right] \mathrm{O}_{4}$ and $\mathrm{LiCo}_{1 / 2} \mathrm{Ni}_{1 / 2} \mathrm{O}_{2}$. Electrochim. Acta 2006, 51, 1651-1655.

125. Lu, W.; Liu, J.; Sun, Y.K.; Amine, K. Electrochemical performance of $\mathrm{Li}_{4 / 3} \mathrm{Ti}_{5 / 3} \mathrm{O}_{4} / \mathrm{Li}_{1+x}\left(\mathrm{Ni}_{1 / 3} \mathrm{Co}_{1 / 3} \mathrm{Mn}_{1 / 3}\right)_{1-x} \mathrm{O}_{2}$ cell for high power applications. J. Power Sour. 2007, 167, 212-216.

126. Jaiswal, A.; Horne, C.R.; Chang, O.; Zhang, W.; Kong, W.; Wang, E.; Chern, T.; Doeff, M.M. Nanoscale $\mathrm{LiFePO}_{4}$ and $\mathrm{Li}_{4} \mathrm{Ti}_{5} \mathrm{O}_{12}$ for high rate Li-ion batteries. J. Electrochem. Soc. 2009, 156, A1041-A1047.

127. Zaghib, K.; Dontigny, M.; Guerfi, A.; Charest, P.; Rodrigues, I.; Mauger, A.; Julien, C.M. Safe and fast-charging Li-ion battery with long shelf life for power applications. J. Power Sour. 2011, 196, 3949-3954.

(C) 2015 by the authors; licensee MDPI, Basel, Switzerland. This article is an open access article distributed under the terms and conditions of the Creative Commons Attribution license (http://creativecommons.org/licenses/by/4.0/). 